\title{
Circulating Levels of Epirubicin Cause Endothelial Senescence While Compromising Metabolic Activity and Vascular Function
}

\author{
Amanda J. Eakin, Tamara Mc Erlain, Aileen Burke, Amy Eaton, Nuala Tipping, \\ Gloria Allocca and Cristina M. Branco*
}

Patrick G. Johnston Centre for Cancer Research, Queen's University Belfast, Belfast, United Kingdom

Anthracycline-based chemotherapy is a common treatment for cancer patients. Because it is delivered intravenously, endothelial cells are exposed first and to the highest concentrations, prior to diffusion to target cells. Not surprisingly, vascular dysfunction is a consequence of anthracycline therapy. While chemotherapy-induced endothelial damage at administration sites has been investigated, the effects of lower doses encountered by distant microvascular networks has not. The aim of this study

OPEN ACCESS

Edited by:

Jiyan Zhang,

Independent Researcher, Beijing,

China

Reviewed by:

N. Rajendra Prasad, Annamalai University, India

Chunying $\mathrm{Li}$,

Georgia State University,

United States

${ }^{*}$ Correspondence:

Cristina M. Branco

C.Branco@qub.ac.uk

Specialty section:

This article was submitted to

Cell Death and Survival,

a section of the journal

Frontiers in Cell and Developmental

Biology

Received: 03 June 2020

Accepted: 28 July 2020

Published: 19 August 2020

Citation:

Eakin AJ, Mc Erlain T, Burke A,

Eaton A, Tipping N, Allocca G and

Branco CM (2020) Circulating Levels

of Epirubicin Cause Endothelial

Senescence While Compromising

Metabolic Activity and Vascular

Function. Front. Cell Dev. Biol. 8:799.

doi: 10.3389/fcell.2020.00799 was to investigate the impact of epirubicin, a widely used anthracycline, on healthy endothelial cells to elucidate its effects on microvascular physiology. Here, endothelial cells were briefly exposed to low doses of epirubicin to recapitulate levels in circulation following dilution in the blood and compound half-life in circulation. Both immediate and prolonged responses to treatment were assessed to determine changes in endothelial function. Epirubicin caused a decrease in proliferation and viability in hUVEC, with lower doses resulting in a senescent phenotype in a large proportion of cells, accompanied by a significant increase in pro-inflammatory cytokines and a significant decrease in metabolic activity. Epirubicin exposure also impaired endothelial function with delayed wound closure, reduced angiogenic potential and increased monolayer permeability downstream of VE-cadherin internalization. Primary lung endothelial cells obtained from epirubicin-treated mice similarly demonstrated reduced viability and functional impairment. In vivo, epirubicin treatment resulted in persistent reduction in lung vascular density and significantly increased infiltration of myeloid cells. Modulation of endothelial status and inflammatory tissue microenvironment observed in response to low doses of epirubicin may predict risk for long-term secondary pathologies associated with chemotherapy.

Keywords: epirubicin, endothelial dysfunction, senescence, inflammation, organ microenvironment

\section{INTRODUCTION}

Chemotherapy is the standard of care for most cancer patients, especially those affected by aggressive cancer types, metastatic or refractory disease (NICE 2020). All chemotherapy is systemic, and mostly administered intravenously, at maximal tolerated doses (Le Tourneau et al., 2009). Even though cytotoxic drugs affect primarily their target cells (cancer cells), their effects are experienced and responded to also by somatic cells. 
Anthracyclines are a family of commonly used chemotherapeutic agents, with demonstrated success in elimination of cancer cells and association with increased survival (EBCTCG, 1988, 2005). Mechanistically, these drugs work by inhibition of topoisomerase II activity, compromising DNA and RNA synthesis, by intercalating nucleic acid chains (Szuławska and Czyz, 2006), which results in cell death, primarily in rapidly dividing cells, with higher DNA replication frequency.

Doxorubicin is the most widely used anthracycline, used in the treatment of malignancies such as breast cancer, bladder cancer, or lymphoma (EBCTCG, 2005; Gianni et al., 2009; Lori et al., 2010; Fukuokaya et al., 2020). The cancer treatment effectiveness of Doxorubicin is, however, accompanied by severe cardiotoxicity, and as a result it has been increasingly replaced by epirubicin, an epimer associated with milder adverse effects (Khasraw et al., 2012). Epirubicin has comparable anti-tumor effectiveness, but very distinct pharmacokinetic properties, permitting a wider safety margin and cumulative doses nearly twice as high as those used for Doxorubicin (Edwardson et al., 2015), which will likely promote its increased implementation in routine cancer treatment.

With increased survival, the long term consequences of anthracycline treatments have become more apparent, and beyond myocardial dysfunction, post-treatment conditions are now known to include hypertension and thrombosis, ultimately resulting in a poorer quality of life (Swain et al., 2003; Jones et al., 2007; Mercuro et al., 2007; Barrett-Lee et al., 2009; Cameron et al., 2016). The usual administration by intravenous route, from which it reaches target cells by diffusion, inevitably exposes endothelial cells (EC) to the highest drug levels, even in organs distant from infusion site, and not surprisingly a severe consequence of anthracycline treatment is vascular dysfunction (Cameron et al., 2016).

Vascular EC are critical in maintaining the tissue microenvironment as they create a barrier, a single cell layer that is both continuous and heterogeneous, between circulating blood and surrounding tissue. They are also responsible for local control of perfusion to match tissue demand and supply (Augustin and Koh, 2017), and are the first responders to systemic signals of both internal or external nature, plastically adjusting flow and permeability to ensure organ homeostasis.

The damage inflicted by chemotherapeutical agents at injection sites has been investigated (Sato et al., 2014). Specifically, a recent study found an association of Doxorubicin treatment with increased EC death, in which a significant inflammatory response, downstream of increased levels of proinflammatory cytokines and mediated by activation of the NFKB pathway was also shown (Sonowal et al., 2018). Doxorubicin has also been associated with senescence of somatic cells, including EC, resulting in reduced regenerative ability, likely behind disruption of endothelial plasticity (Yasuda et al., 2010; Wojcik et al., 2015; Cappetta et al., 2018).

The mechanisms underlying these observations and the impact on co-morbidity associated with cancer treatment are not well understood, but effects on microvasculature in particular can underlie severe and persistent effects on organ function. Importantly, most studies to date explore damage of injection sites (high drug concentrations) (Yamada et al., 2012), and consequent EC death, however, the low level, sublethal doses encountered by the majority of somatic cells has not been meaningfully characterized. The responses and adaptation of surviving EC to cytotoxic exposure may alter or compromise their function and that of the organs in which they reside, including degeneration or indeed potential for onset and success of distant metastases (Kennecke et al., 2010; Martin et al., 2017; Xiao et al., 2018).

The aim of this study is to investigate the consequences of low-level exposure of epirubicin on healthy EC. In spite of its known reduced toxicity in comparison to Doxorubicin, this drug has not been studied in the context of its effects on microvascular physiology and the downstream impact this may have on vascular pathogenesis.

In the present study, EC were exposed to short treatments of physiological doses of epirubicin, to emulate exposure following drug dilution in the blood stream, and accounting for its relatively short half-life (Robert, 1994; Edwardson et al., 2015). The aim was to investigate how surviving EC that endure and adjust to cytotoxic insult may educate the organ microenvironment, to what extent, and the duration and/or reversibility of such EC adaptations.

Human umbilical vein EC (hUVEC) were used to investigate effects on EC survival and function. Additionally, naïve (tumorfree) mice were treated with intravenous epirubicin to assess effects of treatment on lung vascular parameters, considering that lung disease and associated comorbidities are heavily associated with vascular dysfunction (Reiterer and Branco, 2020), and this is also a common metastatic site. Primary microvascular EC (MVEC) were also isolated from lung tissue (Reiterer et al., 2019) to investigate the effects of epirubicin on EC behavior following in vivo exposure.

\section{MATERIALS AND METHODS}

\section{Cell Culture}

hUVEC were maintained in collagen-coated plates, at $37^{\circ} \mathrm{C}$ and at physiological oxygen tensions $\left(5 \% \mathrm{O}_{2}\right)$ and $5 \% \mathrm{CO}_{2}$. Cells were expanded in antibiotic-free medium containing a 1:1 mix of Ham's F12 nutrient mix (21765037, Gibco) and low glucose Dulbecco's Modified Eagle's Medium (DMEM) (D6046, Sigma Aldrich), supplemented with 1\% MEM nonessential amino acids (11140050, Gibco), $2 \mathrm{mM}$ sodium pyruvate (11360070, Gibco), 20 mM Hepes (H0887, Sigma-Aldrich), $10 \mathrm{mg} / \mathrm{mL}$ Heparin (H3149-25kU, Sigma-Aldrich), $7.5 \mathrm{mg} / \mathrm{mL}$ EC growth supplement (E2759, Sigma-Aldrich) and 20\% fetal bovine serum (F7524, Gibco).

\section{Migration Assay}

Cells were grown to $>90 \%$ confluence in a 12 -well plate and incubated with saline or epirubicin at concentrations typically found in circulation 3 or $5 \mu \mathrm{g} / \mathrm{mL}$ for $30 \mathrm{~min}$ followed by replacement with drug-free medium. $10 \mu \mathrm{g} / \mathrm{mL}$ is typical but proved lethal for hUVEC ex vivo. Cells were analyzed immediately (baseline) or allowed to recover for a given period 
before beginning the assay. Prior to the migration assay, growth medium was replaced by serum-free basal medium containing $50 \mu \mathrm{g} / \mathrm{mL}$ Mitomycin C (CAY11435, Cambridge Bioscience) for $1.5 \mathrm{~h}$. This was removed at the start of the assay and a scratch/wound was made by scraping a $1 \mathrm{~mL}$ pipette tip through the middle of each well. Cells were washed twice in PBS before adding growth medium, and images taken at various time points throughout the assay. Wound closure was quantified using Image J software (version 8.0).

\section{Angiogenesis Assay}

$10 \mu \mathrm{L}$ of complete Matrigel (354234, Corning) was loaded onto angiogenesis slides (1B-81506, Thistle scientific) and incubated for at least $30 \mathrm{~min}$ at $37^{\circ} \mathrm{C}$ to solidify the matrix. $>90 \%$ confluent cells grown in 12-well plates were treated, as before, with epirubicin or saline for $30 \mathrm{~min} .4 .5 \times 10^{3}$ cells in $50 \mu \mathrm{L}$ of growth medium were seeded on top of the Matrigel substrate. Images were taken at various time points throughout the assay. Tube formations were analyzed using the "Angiogenesis Analyzer" plug-in for ImageJ.

\section{Permeability Assay}

hUVEC were plated at a density of $4 \times 10^{4}$ cells/well into $8 \mu \mathrm{m}$ Fluoroblok ${ }^{\mathrm{TM}}$ inserts (351152, Appleton Woods Ltd.) in a 24-well companion plate (353504, Analab). Cells were also plated at the same density into a 96-well plate (which have the same surface area as the Fluoroblok ${ }^{\mathrm{TM}}$ inserts) to monitor confluency; when the cells formed a uniform monolayer in the 96-well plates, they were assumed confluent in the inserts, and at that time incubated with saline or epirubicin for $30 \mathrm{~min}$ followed by replacement with drug-free medium. Cells were either assayed immediately after treatment or allowed to recover for 1 day. $1 \mathrm{mg} / \mathrm{mL}$ FITCDextran $70 \mathrm{kDa}$ (46945, Sigma-Aldrich) in growth medium was added to the upper chamber, and medium without FITC-Dextran was added to the lower chamber immediately before the start of the assay. Fluorescent signal $(488 \mathrm{~nm})$ was read every $5 \mathrm{~min}$ for a total of $6 \mathrm{~h}$ using an Omega plate reader (BMG Labtech) set at $37^{\circ} \mathrm{C}, 5 \% \mathrm{O}_{2}$ and $5 \% \mathrm{CO}_{2}$. Signal was normalized to positive control wells (FITC dextran was added to the lower chamber for maximum fluorescence signal), and negative controls (no FITCDextran was added to either chamber); assay also included a no-cell control.

\section{Metabolism Assays}

Local extracellular acidification rate (ECAR) and oxygen consumption rate (OCR) following cytotoxic therapy in hUVEC were measured using a Seahorse XFe96 Analyzer (Agilent) and compared to saline controls. $1 \times 10^{4}$ hUVEC grown at $5 \% \mathrm{O}_{2}$, $5 \% \mathrm{CO}_{2}$ at $37^{\circ} \mathrm{C}$ were seeded on Seahorse microplates pre-coated with $3 \mu \mathrm{g} / \mathrm{mL}$ collagen I (C9791, Sigma Aldrich) in $0.1 \mathrm{M}$ acetic acid and allowed to adhere for at least $12 \mathrm{~h}$. hUVEC were treated with $3 \mu \mathrm{g} / \mathrm{mL}$ epirubicin for $30 \mathrm{~min}$. Medium was replaced with drug-free medium and cells were analyzed immediately (baseline) or after recovering for 1 day. The day before the assay was carried out, Seahorse XF assay Medium was adjusted to a $\mathrm{pH}$ of 7.4 and supplemented with $2.5 \mathrm{mM}$ glutamine for the glycolytic stress test, and with $2.5 \mathrm{M}$ glucose and $100 \mathrm{mM}$ pyruvate for the mitochondrial stress tests. The injection cartridge was hydrated overnight in a $\mathrm{CO}_{2}$ free incubator at $37^{\circ} \mathrm{C}$. To carry out the analysis at non-atmospheric conditions, the Analyzer was placed in a Ruskinn hypoxia chamber and atmosphere equilibrated to $5 \% \mathrm{O}_{2}$ and $0.1 \% \mathrm{CO}_{2}$. The instruments, Seahorse XF Medium (103575, Agilent) and calibrant solution were also equilibrated to the adequate oxygen levels for a minimum of $12 \mathrm{~h}$ prior to the assay. Solutions for injections were prepared fresh immediately before each assay. For the glycolytic stress tests, a final concentration of $10 \mathrm{mM}$ glucose, $1 \mu \mathrm{M}$ oligomycin and $50 \mathrm{mM}$ 2-deoxyglucose were used. For the mitochondrial stress tests, compounds were added at final concentrations of $1 \mu \mathrm{M}$ oligomycin, $0.5 \mu \mathrm{M}$ FCCP and $0.5 \mu \mathrm{M}$ Antimycin A/Rotenone. A final volume of $200 \mu \mathrm{L}$ was kept consistent across test and control wells, with vehicle injections added to negative controls to allow volume normalization throughout the assay. Each measurement followed a $25 \mathrm{~min}$ equilibration period to establish the baseline levels, and was composed of a 5 min mix 0 min -2 min measure cycle which lasted as recommended by the manufacturer. All Seahorse measurements were normalized to the $\mu \mathrm{g}$ of total protein concentrations in each well, quantified with Bicinchoninic acid (BCA) assay (23225, Thermo Fisher). Seahorse Wave software and GraphPad were used to statistically analyze these data.

\section{TUNEL Assay}

The TUNEL assay was performed using the Invitrogen by Thermo Fisher Scientific Click-iT ${ }^{\mathrm{TM}}$ TUNEL Alexa Fluor ${ }^{\mathrm{TM}} 488$ Imaging Assay (C10245, Thermo), as per the manufacturer's instructions. hUVEC were seeded onto collagen-coated glass chamber slides and maintained until they reached $80 \%$ confluence, with medium changed daily. hUVEC were treated with epirubicin for $30 \mathrm{~min}$ as described above. Slides were washed in PBS then fixed with pre-cooled acetone for $7 \mathrm{~min}$ followed by three washes in PBS. The cells were permeabilized with $0.4 \%$ Triton-X in PBS for $20 \mathrm{~min}$ at room temperature. A $10 \mathrm{~min}$ incubation with $\mathrm{TdT}$ reaction buffer at room temperature was followed by a $1 \mathrm{~h}$ incubation at $37^{\circ} \mathrm{C}$ in a humidified chamber with the TdT reaction cocktail (TdT reaction buffer, EdUTP and $\mathrm{TdT}$ ). The slides were then washed twice in PBS containing 3\% BSA, and the Click-iT reaction cocktail (Click-iT reaction buffer and additive) was added to the slide chambers and incubated for $30 \mathrm{~min}$ at room temperature, protected from light, and finally washed three times for $5 \mathrm{~min}$ in PBS containing 3\% BSA. Nuclei were stained by incubation with $2 \mu \mathrm{g} / \mathrm{mL}$ Hoechst 33342 for $15 \mathrm{~min}$ at room temperature, protected from light. After two 5 min washes in PBS, slides were mounted with Vectashield Antifade mounting medium (H-1000, Vectorlabs) and imaged the following day using a Leica DM5500 fluorescent microscope.

\section{Senescence Assay}

Senescence was assayed using a commercially available beta Galactosidase staining kit (ab102534, Abcam) as per the manufacturer's instructions. hUVEC were plated onto collagen coated 12-well plates and grown until 80\% confluence. Following epirubicin treatment, hUVEC were washed briefly in PBS before addition of the fixative solution (provided) and incubated for 
$15 \mathrm{~min}$ at room temperature. The cells were washed twice with PBS before addition of the staining solution (staining solution, staining supplement and X-Gal in DMSO). The plate was covered and incubated at $37^{\circ} \mathrm{C}$ overnight inside a sealed bag to prevent any $\mathrm{pH}$ changes as a result of $\mathrm{CO}_{2}$ levels in the $37^{\circ} \mathrm{C}$ incubator that may affect color development. The cells were washed briefly in PBS the following day and were counterstained with Nuclear Fast Red (N3020, Sigma-Aldrich) for 5 min then washed twice in PBS before imaging.

\section{Transcription Factor Assay}

Transcription factor activation was assessed using the Signosis TF Activation Profiling Plate Array I (FA-1001-NF, Signosis). hUVEC were grown in six-well plates until full confluence was reached. Wells were treated as before in triplicate with either saline or $3 \mu \mathrm{g} / \mathrm{mL}$ epirubicin. Following incubation, cells were left for 1 day in complete growth medium. The supernatants were removed, and nuclear protein was extracted using the Signosis Nuclear Extraction kit, according to the manufacturer's instructions (SK-0001, Signosis). Nuclear protein was quantified using a BCA assay, as above, and $15 \mu \mathrm{g}$ of nuclear protein per condition was used for the assay. The assay was carried out according to the manufacturer's instructions, and results quantified with an OMEGA plate reader (BMG Labtech).

\section{Cytokine Screening}

Cytokine analysis was carried out using the Biotechne Human Cytokine Array (ARY005B, Biotechne). hUVEC were grown in a six-well plate until confluent. Wells were treated as before, in triplicate, with either saline or $3 \mu \mathrm{g} / \mathrm{mL}$ epirubicin. Following treatment, cells were left to recover for 1 day in drug-free medium. The supernatants were removed and frozen at $-80^{\circ} \mathrm{C}$ until required for the assay. The assay was carried out by incubating neat media with pre-probed membranes (provided), washed and detected according to the manufacturer's instructions. Blots were imaged using a Syngene image analysis system with GeneSys software, and signal was quantified and analyzed using ImageJ.

\section{Real-Time Polymerase Chain Reaction (qPCR)}

RNA was extracted from fast-frozen epirubicin-treated hUVEC using a Purelink RNA mini kit (12183018A, ThermoFisher) followed immediately by a DNAse Treatment using an RNAsefree DNAse kit (79254, Qiagen). RNA was quantified using a Nanodrop and a minimum of $200 \mathrm{ng}$ was used for reverse transcription cDNA synthesis. cDNA synthesis was performed using the Roche Transcriptor First Strand Kit (04896866001, Roche). qPCR was carried out using cDNA diluted 1:7, the Roche LightCycler 480 SYBR green I Master (04707516001, Roche) and Quantitect primers; $\beta$-Actin (QT00095431), VEGFA (QT01682072) and NOS3 (QT00095431). Target signal is normalized to $\beta$-Actin and presented as average fold change (treatment/control) \pm SEM.

\section{Animal Experiments}

The study was conducted under project license PPL2859, approved by the NI Department of Health/ United Kingdom Home Office and the institutional ethical committee, and compliant with the ethical principles of the Animals (Scientific Procedures) Act 1986. C57BL/6 mice (aged 6-8 weeks) received $150 \mu \mathrm{L}$ of $2 \mathrm{mg} / \mathrm{mL}$ ( $0.3 \mathrm{mg}$ for a mouse of $\sim 20 \mathrm{~g}$ ) epirubicin or saline control by intravenous route (tail vein); This corresponds to a sub-clinical dose of epirubicin, approximating at $15 \mathrm{mg} / \mathrm{kg}$, compared to an average clinical dose of approximately $30 \mathrm{mg} / \mathrm{kg}$ in human patients (U.S. Department of Health and Human Services et al., 2005). Lungs were collected from one group of animals 1 day following injection to assess acute effects while allowing for detection of vascular changes, which are not immediate, or after 7 days, to assess if observed effects reversed, persisted or aggravated following clearance of cytotoxic insult. A third group of animals received two injections, one on day 0 and one on day 3 to investigate if there were visible changes in vascular and inflammatory parameters with increased cumulative dose. Treatment groups had either five animals ( 1 and 7 days re-injected) or four animals (7 days, one injection), and the same number of control animals per group, injected with sterile saline. Lungs were inflated with $10 \%$ formalin and maintained in fixative overnight. Following multiple washes in PBS, tissue was embedded in paraffin for sectioning and immunofluorescent staining. Data from saline groups were ultimately combined and presented as one control group, following confirmation that there were no differences between the three saline-treated groups.

\section{Murine Endothelial Cell (EC) Isolation and Culture}

Primary microvascular EC (MVEC) were isolated from lungs on day 1 and day 7 following treatment to investigate proliferation, viability and function ex vivo. Lung tissue was removed following cervical dislocation, and stored in cold DMEM for up to $1 \mathrm{~h}$ until processing. Five mice were used per group. EC were isolated as previously described (Reiterer et al., 2019) expanded and maintained at $37^{\circ} \mathrm{C}, 5 \% \mathrm{CO}_{2}$ and $10 \% \mathrm{O}_{2}$ (physiological for lung EC) in the same medium as described for hUVEC (above). All functional assays were performed in triplicate, using cells at passage 1 .

\section{Immunofluorescent (IF) Staining}

Paraffinized tissue from murine lung was sectioned $(10 \mu \mathrm{m})$ using a microtome and mounted onto slides. Prior to staining, slides were deparaffinized in Histoclear II (H2779, Sigma-Aldrich) and rehydrated through graded alcohols. Acidic antigen retrieval was performed using a citrate-based buffer. After 3 washes in PBS slides were incubated for $10 \mathrm{~min}$ in $3 \% \mathrm{H}_{2} \mathrm{O}_{2}$ in methanol and blocked with Universal Protein Blocking Agent (GTX30963, Stratech) for $7 \mathrm{~min}$. Slides were then incubated with Sudan Black (199664, Sigma Aldrich) for $10 \mathrm{~min}$. After 3 washes in PBS, slides were incubated overnight at $4^{\circ} \mathrm{C}$ in primary antibody [goat anti-mouse Podocalyxin (AF1556, R\&D systems) for EC detection ( $\mathrm{Li}$ et al., 2001), rat anti-mouse Mac-2 (Galectin-3, 125402, Biolegend) for myeloid cells (Ho and Springer, 1982), 
alpha smooth muscle actin - Cy3 (C6198, Sigma Aldrich) to stain pericytes (Babai et al., 1990)]. Slides were washed 3 times in PBS and then incubated for $2 \mathrm{~h}$ in secondary antibody [1:200 dilution AlexaFluor647 conjugated donkey anti-goat (ab150135, Abcam) and 1:200 dilution FITC-conjugated rabbit anti-rat (ab6730, Abcam)] protected from light. Finally, slides were incubated with $2.5 \mu \mathrm{g} / \mathrm{mL} \mathrm{4}$, 6-Diamidino-2-Phenylindole, Dihydrochloride (DAPI) (D1306, Thermo) for $10 \mathrm{~min}$ and mounted with Vectashield Antifade mounting medium (H-1000, Vectorlabs). Imaging was performed the next day, using a Leica DM5500 fluorescent microscope at $20 \times$ magnification. Eight non-consecutive sections were stained per animal, and 3 images were taken per section, subsequently analyzed using ImageJ software. Background correction was performed across all images by subtracting background with a rolling ball radius of 50 pixels. The plug-in "Vessel Analysis" was used to quantify the vascular density and vessel diameter. The vascular density was quantified using the green color channel and enhancing local contrast to block size $=9 ; \max$ slope $=4.00$. The image was then made binary and the vascular density function. Average vessel diameter was determined by enhancing local contrast to block size $=9$; $\max$ slope $=4.00$, then adjusting the threshold to black and white and using the diameter measurements function. Pericyte to EC ratio was measured by adjusting the threshold to black and white and setting measurements to "Area Fraction" and "Limit to Threshold" before measuring. This was repeated for both color channels, then the pericyte signal was divided by the EC signal and the average taken per section. Macrophages were counted both by hand and using the particle analysis function on ImageJ. Both methods produced similar results and so the automated method was used for efficiency. The parameters set for particle analysis were 1) a size of greater than 80 pixels and 2) a circularity of between $0.45-1.00$. Following analyses of all parameters, no differences were seen between the three saline control groups, those were pooled when plotted against the treatments (Figures 6, 7).

\section{RESULTS}

\section{Exposure to Subclinical Doses of Epirubicin Persistently Compromises hUVEC Proliferation and Viability}

Endothelial Cell are essential for organ homeostasis and tissue function, performing localized regulatory roles that maintain adequate exchange of nutrients, gases and signals. hUVEC were used to investigate how this cell type responds to the effects of circulating epirubicin. Time of exposure and concentrations for treatments in vitro were determined based on compound half-life and the concentration following dilution of typical clinical doses in the blood stream (Robert, 1994), to investigate the effects of the drug at organs distant from the site of infusion. The average concentration found in circulation of patients $(10 \mu \mathrm{g} / \mathrm{mL})$ receiving the typical clinical epirubicin dose (90 mg/kg) proved too toxic for a hUVEC monolayer, and most cells did not survive the treatment (data not shown). Therefore, confluent monolayers were treated for $30 \mathrm{~min}$ with lower doses of epirubicin ( 3 or $5 \mu \mathrm{g} / \mathrm{mL}$ ), which was subsequently replaced with drug-free growth medium.

Total cell counts following treatment was shown to decrease after 1 day for cells treated with $5 \mu \mathrm{g} / \mathrm{mL}$ (Figure 1A). This is also illustrated by a gradual decrease in confluency (Supplementary Figure S1A), where more space is observed between cells. For the first 2 days of recovery from epirubicin exposure, attached cells remained viable (as determined by Trypan blue exclusion method), but viability decreased in treated cells after 3 days (Figure 1B), suggesting that the cytotoxic effects of the drug on hUVEC can persist for several days following exposure.

TUNEL staining of hUVEC following epirubicin treatment shows, predictably, a dose-dependent increase in hUVEC apoptotic cell death (Figure 1C); cell number per field of view, quantified by batch analyses (ImageJ) (Figure 1D, upper panel) decreases with increased epirubicin dose, with a larger proportion of dead or dying cells particularly significant in cells treated with $5 \mu \mathrm{g} / \mathrm{mL}$ epirubicin. Cells that persist following $3 \mu \mathrm{g} / \mathrm{mL}$ show proportionally less TUNEL staining and appear to remain viable for longer time (Figure 1D, lower panel).

\section{Viable EC Exposed to Epirubicin Become Senescent}

During recovery following exposure to epirubicin, changes in confluency and cell morphology were observed, where cells appear enlarged and flattened (Supplementary Figure S1B), usually characteristic of cells undergoing senescence. It has been shown in other models that chemotherapy may cause senescence in somatic cells (Ewald et al., 2010), and this was investigated as a possible effect on hUVEC. The well-established Senescence-Associated $\beta$-Galactosidase (SA- $\beta$-Gal) method was used to detect senescing hUVEC following epirubicin treatment (Figure 2A). Total number of cells per field of view were quantified (Figure 2B, upper panel), and the relative proportion of senescing cells (Figure 2B, lower panel) is seen to dramatically increase immediately after exposure and is maintained for at least 2 days after drug removal (Figure 2B). These results show low concentrations seen in small microvascular networks distant from injection sites can trigger endothelial senescence. Cell senescence is associated with a secretory pattern that is primarily pro-inflammatory [senescence associated secretory profile, or SASP (Coppé et al., 2008; Kuilman et al., 2008; Wajapeyee et al., 2008)]. An angiocrine screen (Figure 2C) was performed on hUVEC-conditioned medium, obtained from cells that recovered for 1 day in drug-free medium to assess EC-derived signaling, and shows that exposure to $3 \mu \mathrm{g} / \mathrm{mL}$ of epirubicin caused a significant increase in the secretion of many pro-inflammatory cytokines (Figure 2D), consistent with SASP signature, and including monocyte/macrophage recruitment and activation factors such as CCL2 and granulocyte colony stimulating factor (G-CSF) (Coppé et al., 2008; Eggert et al., 2016), as well as pro-inflammatory cytokines IL-6 and IL-8.

\section{Exposure to Epirubicin Impairs Endothelial Function}

To further evaluate if the effects of epirubicin influences endothelial function, essential parameters of endothelial behavior 
A

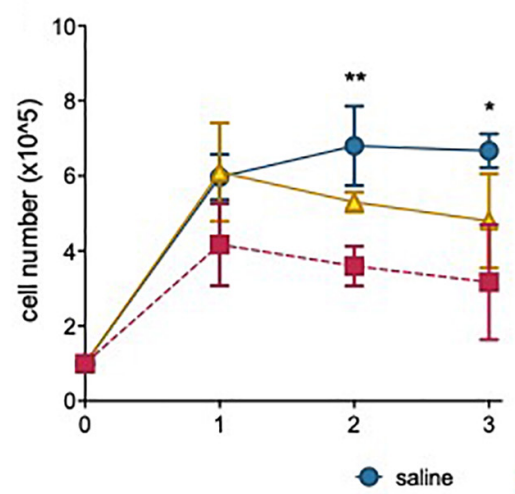

B

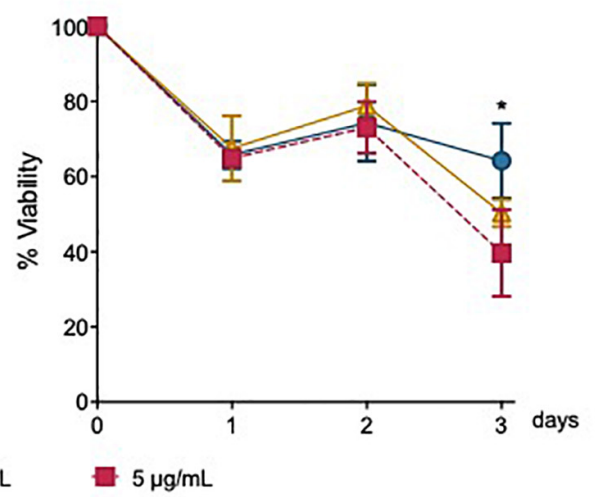

C

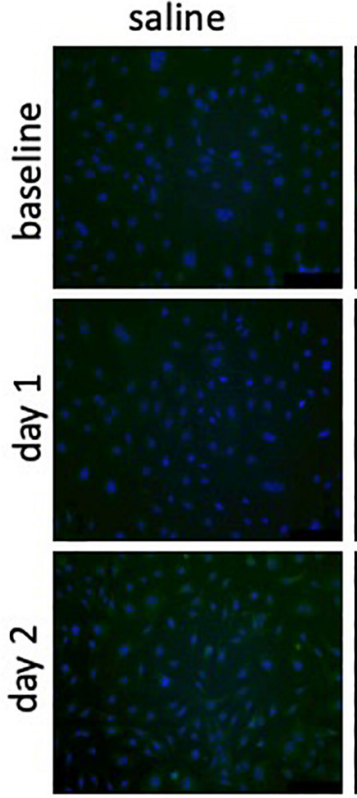

$3 \mu \mathrm{g} / \mathrm{ml}$
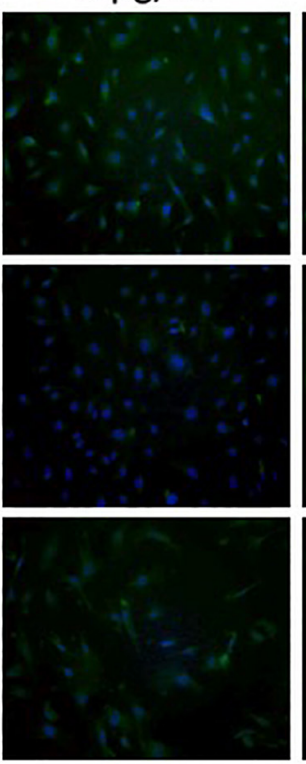

$5 \mu \mathrm{g} / \mathrm{ml}$

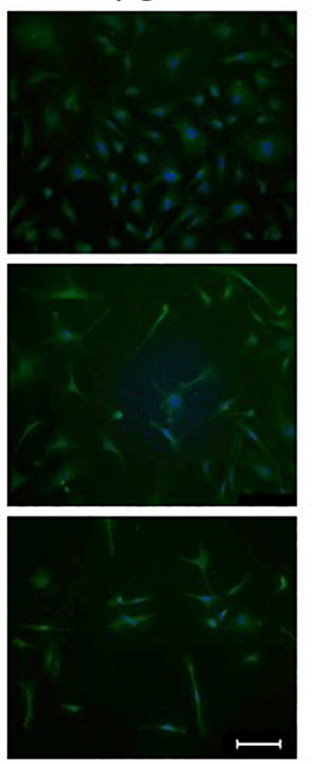

D
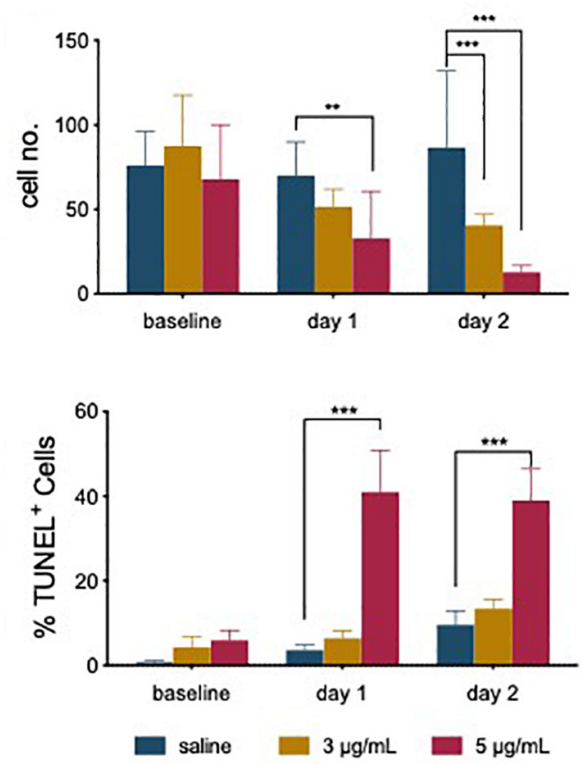

FIGURE 1 | Epirubicin treatment reduces hUVEC proliferation and viability. Confluent hUVEC monolayers were exposed for 30 min to epirubicin ( 3 or $5 \mu$ g/mL) or equal volume of saline. (A) Total number of attached cells were counted immediately after treatment (baseline) and again following 1-3 days of recovery in drug-free medium. (B) Cell viability was assessed using Trypan Blue exclusion. Data displayed as mean $\pm \mathrm{SD}$, significance assessed by $t$-tests and ${ }^{\star} p<0.05$, ${ }^{\star *} p<0.01$, $n=3$. For panels (A) and (B), no significant difference was observed between saline and $3 \mu \mathrm{g} / \mathrm{mL}$, asterisks represent significance between saline and $5 \mu \mathrm{g} / \mathrm{mL}$ epirubicin. (C) Representative images of TUNEL-stained control and epirubicin-treated hUVEC, scale bar = $100 \mu \mathrm{m}$. (D) Number of cells per field of view (upper panel) and relative proportion of TUNEL positive cells detected per field of view, represented as average percentage (lower panel). Image analyses and quantification done using ImageJ (8.0). Statistical significance was assessed by Two-Way ANOVA with Bonferroni Correction, and ${ }^{\star} p<0.05,{ }^{\star \star} p<0.01,{ }^{\star \star \star} p<0.001$.

were measured. All functional parameters were performed in cells for which viability was confirmed (Supplementary Figure S2A).

The ability to form and regenerate monolayers is essential in maintaining vascular integrity during angiogenesis and wound healing, and a property that relies on endothelial migratory capacity. This parameter was quantified using a scratch assay, in the presence of mitomycin, and wound closure was measured over time (Figure 3A). Cells exposed to epirubicin showed a delay in wound closure, but significance was only established for cells treated with a higher dose $(5 \mu \mathrm{g} / \mathrm{mL})$, when the assay was performed after 1 day of recovery (representative images for this time point are shown in Figure 3B). Barrier function was also assessed following 1 day recovery, using an assay in which the movement of FITC-labeled $70 \mathrm{kDa}$ Dextran across a
hUVEC monolayer was measured in real-time. Results presented in Figure 3C show that permeability increased significantly following epirubicin treatment. This phenotype is associates with internalization of VE-cadherin, the key adherens molecule in EC, responsible for vascular integrity and stability of ECcell adhesion. VE-cadherin signal shifts from the membrane to cytoplasm following epirubicin treatment, and this correlated with cell dissociation, observed by the appearance of gaps between hUVEC (Supplementary Figure S2B).

Angiogenic potential was also assessed using a tube formation assay (Figure 3D), where cells were assayed immediately after treatment (upper panel), and after 1 day (middle panel) and 2 days (lower panel) recovery. Images were collected at different time points and analyzed using ImageJ software to 


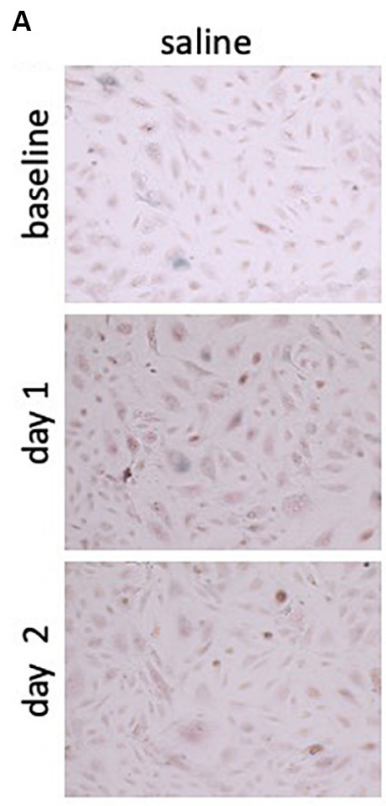

C

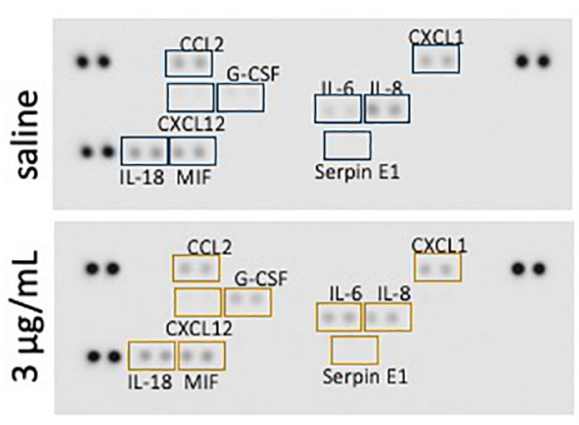

$3 \mu \mathrm{g} / \mathrm{mL}$

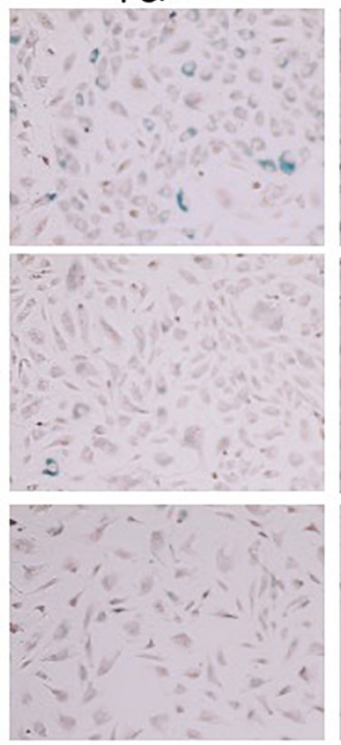

B

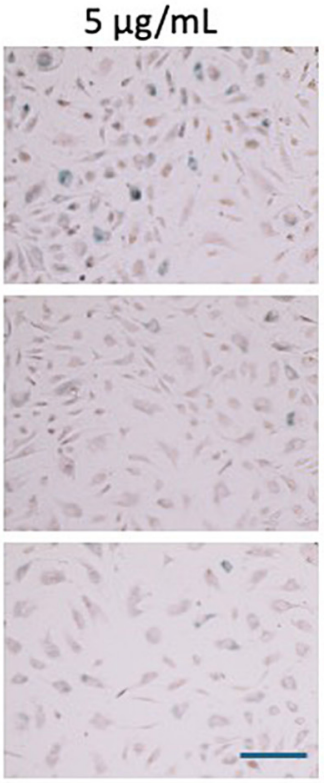

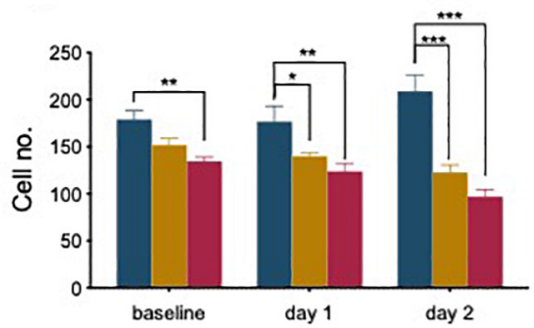

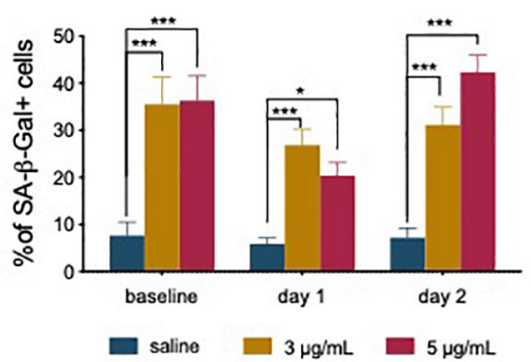

D

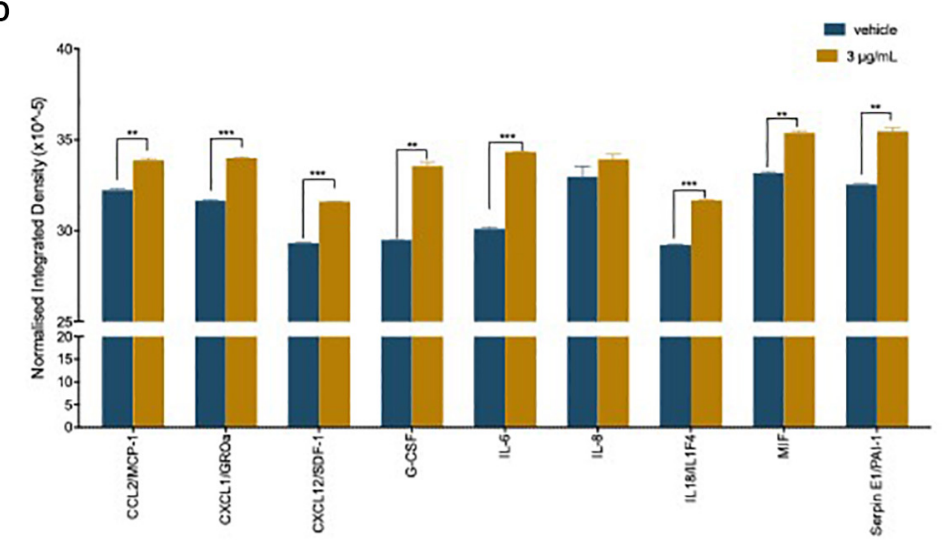

FIGURE 2 | Epirubicin treatment induces senescence in hUVEC. (A) Representative images of saline and epirubicin-treated hUVEC detected using senescence marker SA- $\beta$-gal, and counter-stained with Nuclear Fast Red. Images were obtained on an EVOS brightfield microscope at $20 \times$ magnification, scale bar $200 \mu \mathrm{m}$. (B) Number of cells per field of view (upper panel) and the average percentage of SA- $\beta$-gal positive cells (lower panel); Data displayed as mean \pm SEM ( $n=3$ ). Statistical significance was assessed by Two-Way ANOVA with Bonferroni Correction, and ${ }^{\star} p<0.05$, ${ }^{\star *} p<0.01$, ${ }^{\star \star \star} p<0.001$. (C) Blot image of cytokine panel of hUVEC-conditioned medium collected 1 day after 30 min treatment with saline or $3 \mu \mathrm{g} / \mathrm{mL}$ epirubicin. (D) Densitometry analysis of detectable targets in (C) was carried out using the raw integrated density function on ImageJ software. Data displayed as mean $\pm \mathrm{SD}$. Unpaired t-tests were used for analysis, and ${ }^{*} p<0.05$, ${ }^{* *} p<0.01, n=2$.

systematically quantify number of branches (left) and junctions (right) formed in each condition. Tube formation in saline controls peaked between $3 \mathrm{~h}$ and $5 \mathrm{~h}$, thus representative images for the $5 \mathrm{~h}$ time point are shown (Figure 3E), which also represents the time point at which most significant differences were seen across experimental groups. hUVEC ability to form networks is impaired immediately and significantly after treatment (Figure 3D, upper panel, baseline), where untreated hUVEC form more complex patterns with a higher number of branches and junctions. Interestingly, following recovery for 1 days (Figure 3D, middle panel), cells exposed to $5 \mu \mathrm{g} / \mathrm{mL}$ of epirubicin show a higher number of branches than those exposed to $3 \mu \mathrm{g} / \mathrm{mL}$. After 2 days in drug-free medium, cells treated with the lower epirubicin dose show an angiogenic potential comparable to that of untreated cells (Figure 3D, lower panel), whereas cells exposed to $5 \mu \mathrm{g} / \mathrm{mL}$ lose the ability to form networks. Representative figures for each experiment (baseline and two recovery time points) are shown in Figure 3E.

In order to investigate if these functional differences were seen to have an underlying transcriptional control, a Transcription Factor (TF) activation assay was carried out for cells treated with the lower dose of $3 \mu \mathrm{g} / \mathrm{mL}$ epirubicin, following 1 day recovery (Supplementary Figure S3A). Most TF activity decreases in response to epirubicin, with the most striking decrease observed for SMAD and Sp1, both of which have been associated with VEGF activity (Pagès and Pouysségur, 2005; Lin et al., 2016). 
A
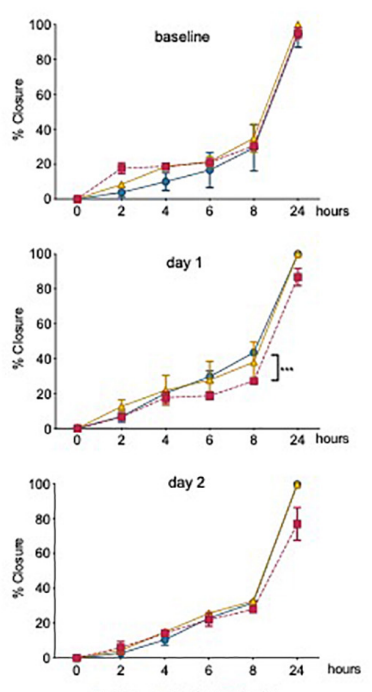

C

- saine $+3 \mathrm{ug} / \mathrm{mL}=5 \mathrm{\mu g} \mathrm{mL}$

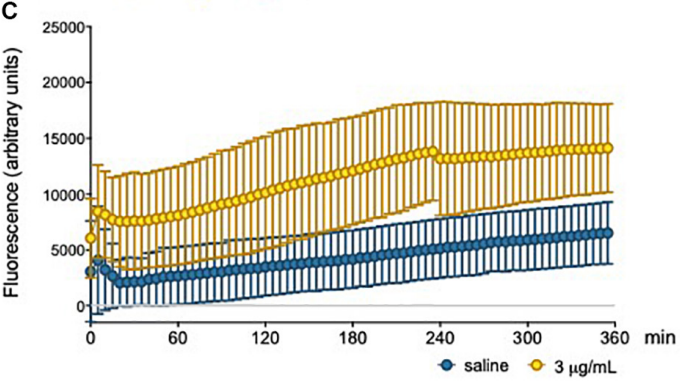

B

ร

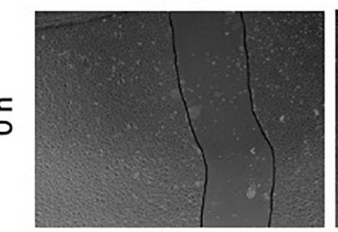

$\frac{c}{\infty}$
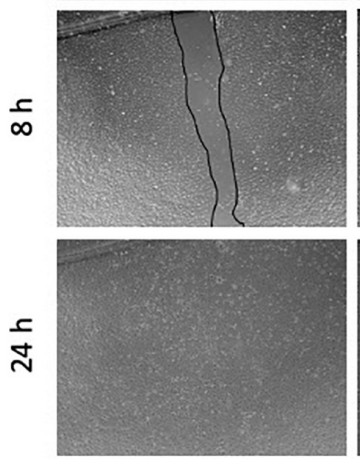

$3 \mu \mathrm{g} / \mathrm{mL}$
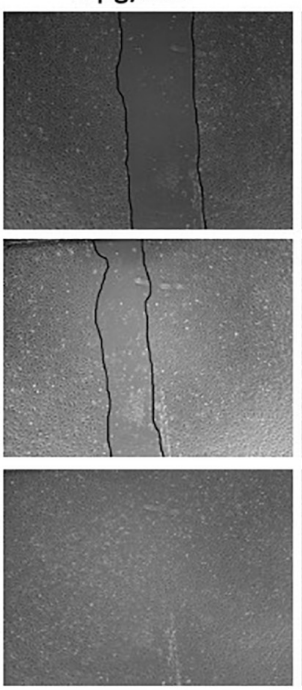

\section{$5 \mu \mathrm{g} / \mathrm{mL}$}
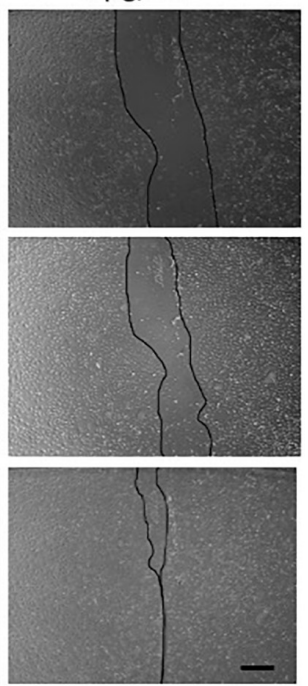

D
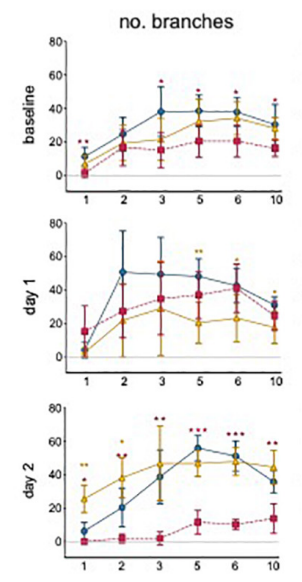

no. junctions
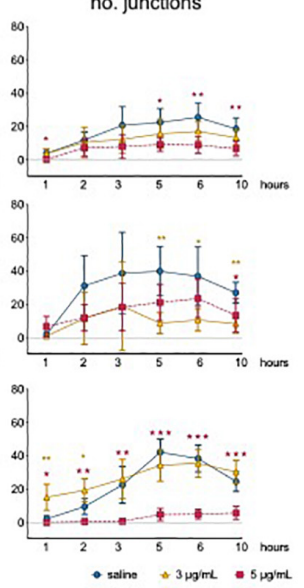

E

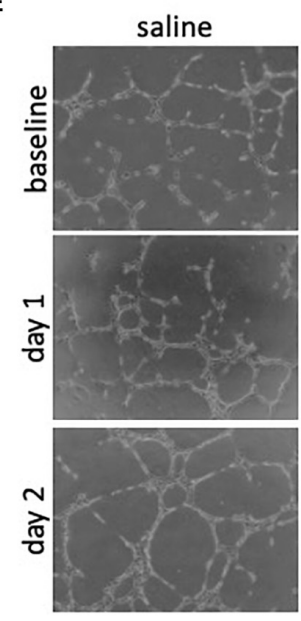

\begin{tabular}{|c|c|c|c|}
\hline AUC & SE & $95 \% \mathrm{Cl}$ & $\mathrm{p}$ value \\
\hline 0.9985 & 0.00170 & $\begin{array}{c}0.9951 \text { to } \\
1.002\end{array}$ & $\begin{array}{c}\mathrm{P}<0.01 \\
\ldots *\end{array}$ \\
\hline
\end{tabular}

$3 \mu \mathrm{g} / \mathrm{mL}$

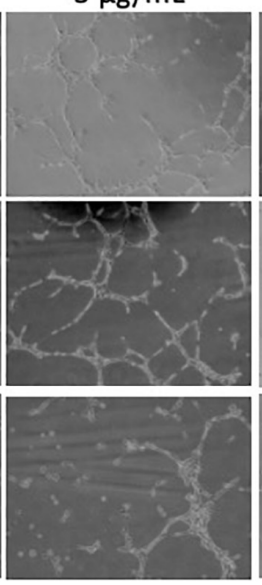

$5 \mu \mathrm{g} / \mathrm{mL}$

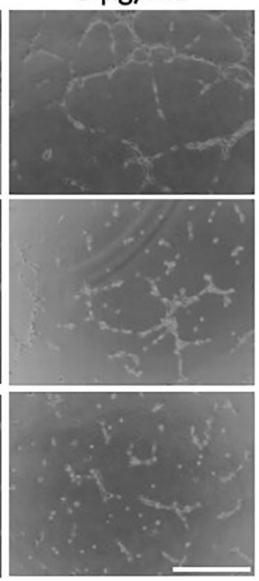

FIGURE 3 | Low dose epirubicin compromises endothelial migration, barrier function and angiogenic potential. (A) Migration assay with viable epirubicin or saline-treated hUVEC, performed in the presence of Mitomycin-C. Assays were performed immediately after exposure (baseline, top panel), 1 day (middle panel) or 2 days (lower panel) recovery in drug-free medium. Images of 2 wells per treatment were collected at regular intervals for up to $24 \mathrm{~h}$, and the area of the scratch was quantified using ImageJ software and converted to percentage of closure. Data displayed as mean\% closure \pm SD; experimental groups were compared at each time point using unpaired $t$-tests, and ${ }^{*} p<0.05,{ }^{* \star} p<0.01,{ }^{* \star *} p<0.001$. (B) Representative images of migration assay from cells 1 day after treatment, scale bar $500 \mu \mathrm{m}$. (C) Permeability assay detecting FITC-dextran $(70 \mathrm{kDa})$ signal as the compound moved through hUVEC monolayer 1 day after epirubicin treatment. Area under the curve (AUC) was compared between treatments, and standard error of the mean (SE) were calculated using GraphPad Prism and shown in adjacent table. (D) Tube formation assays were performed immediately after incubation (baseline), 1 and 2 days after recovery in drug-free medium. Number of branches and junctions were quantified using the "Angiogenesis Analyzer" plug-in for ImageJ; Data represents mean \pm SD $(n=5)$. Red stars represent comparisons between saline and $5 \mu \mathrm{g} / \mathrm{mL}$ epirubicin, yellow asterisks represent comparisons between saline and $3 \mu \mathrm{g} / \mathrm{mL}$ epirubicin. Unpaired $t$-tests were used for analysis of each time point, ${ }^{*} p<0.05,{ }^{* \star} p<0.01,{ }^{* \star *} p<0.001$. (E) Representative images of tube formation assays at the $5 \mathrm{~h}$ time point, scale bar $500 \mu \mathrm{m}$. 
Consistently, 1 day after treatment, VEGF mRNA levels decrease dramatically. However, after 2 day an increase is observed to much higher levels than saline controls, and more so in cells treated with the lower epirubicin dose $(3 \mu \mathrm{g} / \mathrm{mL})$. One other key molecular marker of EC health and function is the endothelial nitric oxide synthase (eNOS), which is essential for vascular tone, intercellular signaling and local perfusion homeostasis (Heiss et al., 2015). NO signaling has also been associated with vascular defects following epirubicin treatment (Gajalakshmi et al., 2013); eNOS transcript levels decrease in a dose-dependent manner, but also transiently (with a slight increase at day 2 compared to day 1) (Supplementary Figure S3B).

In summary, these data suggest that there is both a doseand time-dependent effect on endothelial response to epirubicin. Cells exposed to higher concentrations respond to angiogenic stimuli during the early recovery phase, but fail to maintain that ability (Figure 3D, middle panel). However, cells that are exposed to milder toxicity $(3 \mu \mathrm{g} / \mathrm{mL}$ ) resume the angiogenic potential after 2 day to levels comparable to the saline-treated controls, and this is consistent with a decrease (day 1) followed by an increase (day 2) in a major angiogenesis mediator (VEGF, Supplementary Figure S3B).

\section{Metabolic Activity Is Compromised in hUVEC Exposed to Epirubicin}

It has been demonstrated that endothelial metabolism governs, to a significant extent, endothelial function (Bierhansl et al., 2017). To evaluate metabolic activity in hUVEC exposed to epirubicin, cells were subjected to mitochondrial stress tests (Figures 4A,B) and glucose stress tests (Figures 4C,D). These parameters were evaluated immediately after treatment (baseline) or after cells had been allowed 1 day to recover, using a Seahorse metabolic analyzer (Agilent).

In both time points (baseline and 1 day recovery), cells exposed to epirubicin show a significant decrease in oxygen consumption rate (OCR) (Figure $\mathbf{4 A}$ ), but the decrease in mitochondrial respiratory parameters compared to control cells is more marked 1 day after treatment (Figure 4B), suggesting that mitochondrial reprogramming continues several hours after exposure in viable EC. Glycolytic activity is also seen to decrease in response to epirubicin (Figure 4C), however, unlike the gradual changes seen in oxidative phosphorylation, this shift happens sharply and immediately after the treatment (baseline) and is maintained for at least 1 day after exposure (Figure 4D). In both cases, there is a clear decrease in metabolic activity, which can be a result of decreased energetic demand following onset of senescence, or, conversely, a senescent phenotype as a result of a decrease in energy availability. Consequent decrease in ATP availability is consistent with a significantly reduced (energy demanding) transcriptional activity (Supplementary Figure S3).

\section{Lung MVEC Isolated From Mice Treated With Epirubicin Show Decreased Viability and Migration}

Informed by the characterization of the changes imposed on surviving EC by sublethal levels of epirubicin in a well-established in vivo model (hUVEC), it was critical to investigate if these to any extent mirrored in MVEC, which are a more plastic and versatile EC than their venous counterparts (Dejana et al., 2017); MVEC are cells that locally refine and coordinate tissue demands with systemic availability and distant signals. To assert if the cytotoxic insult is similarly perceived and responded to by MVECs in vivo, naïve C57BL/6 mice were treated with a low clinical dose of epirubicin (approximately at $13.6 \mathrm{mg} / \mathrm{kg}$ ). Lung MVECs were subsequently isolated either 1 or 7 days after injection (Figure 5A), to investigate if effects were transient, persistent or only detectable after enough time was allowed for remodeling, and this was determined based on specific properties of epirubicin hepatic clearance (Edwardson et al., 2015). Following the establishment of a MVEC culture, cells were trypsinized and plated at the same density (passage 1,P1), and total and viable cells were counted every day for 3 days (Figure 5B) using a trypan blue exclusion method. Number and relative viability of cells isolated 1 day after treatment are similar to those obtained from mice that received saline injections. However, lung MVEC obtained from mice 1 week after epirubicin injection proliferated slower and had slightly compromised viability, which is significant after 3 days in $\mathrm{P} 1$.

To assess if this change in proliferation had functional implications, as suggested by hUVEC responses (Figures 3A,B) a migration assay was performed with $\mathrm{P} 1$ primary lung MVEC, in the presence of mitomycin C (as for Figure 3). Again, as seen for proliferation and viability, cells isolated from mice 7 days after epirubicin injection had significantly impaired migration compared to the ones obtained from saline controls (Figure 5C). These data demonstrated that changes in MVEC behavior occur in vivo, but are not seen with immediate effect, suggesting that adaptation involves endothelial reprogramming and not just a transient response. Interestingly, the effect on cells isolated 1 day after injection is not seen even after 1 week in culture, and it is possible that the adaptive response seen in vivo is interrupted or reversed by excess growth factors or nutrients present in growth medium.

\section{Epirubicin Causes a Decrease in Lung Vascular Density}

The lung microvasculature is at the heart of lung function, and efficient gas exchange relies entirely on the seamless interface between a large epithelial surface in contact with a correspondingly large endothelial surface, accomplished with a dense endothelial network. Whole lung tissue from saline control and epirubicin-treated mice were fixed and paraffin-embedded for immunofluorescent analysis. Two groups of mice received one injection of epirubicin (as in Figure 5) and tissue was collected after 1 or 7 days. A third group of mice was treated with two epirubicin doses 3 days apart, to evaluate cumulative effects (Figure 6A). The mice were weighed at the beginning and end of the study, and no significant changes were observed in the control or treated groups. Sections of $10 \mu \mathrm{m}$ were stained for EC (Podocalyxin, (Li et al., 2001) and pericytes ( $\alpha$-SMA, (Babai et al., 1990); nuclei were detected with DAPI and representative 
A

\section{Mitochondria Stress tests}
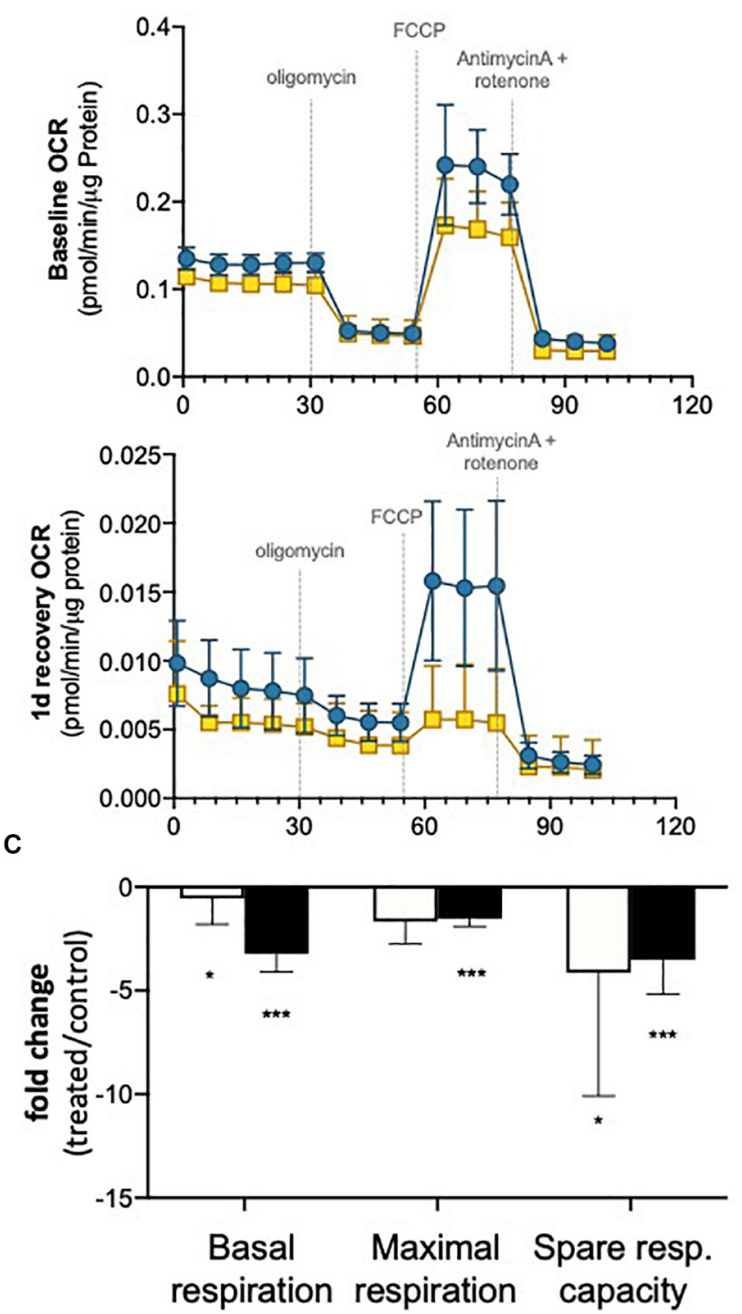

B

\section{Glucose Stress tests}
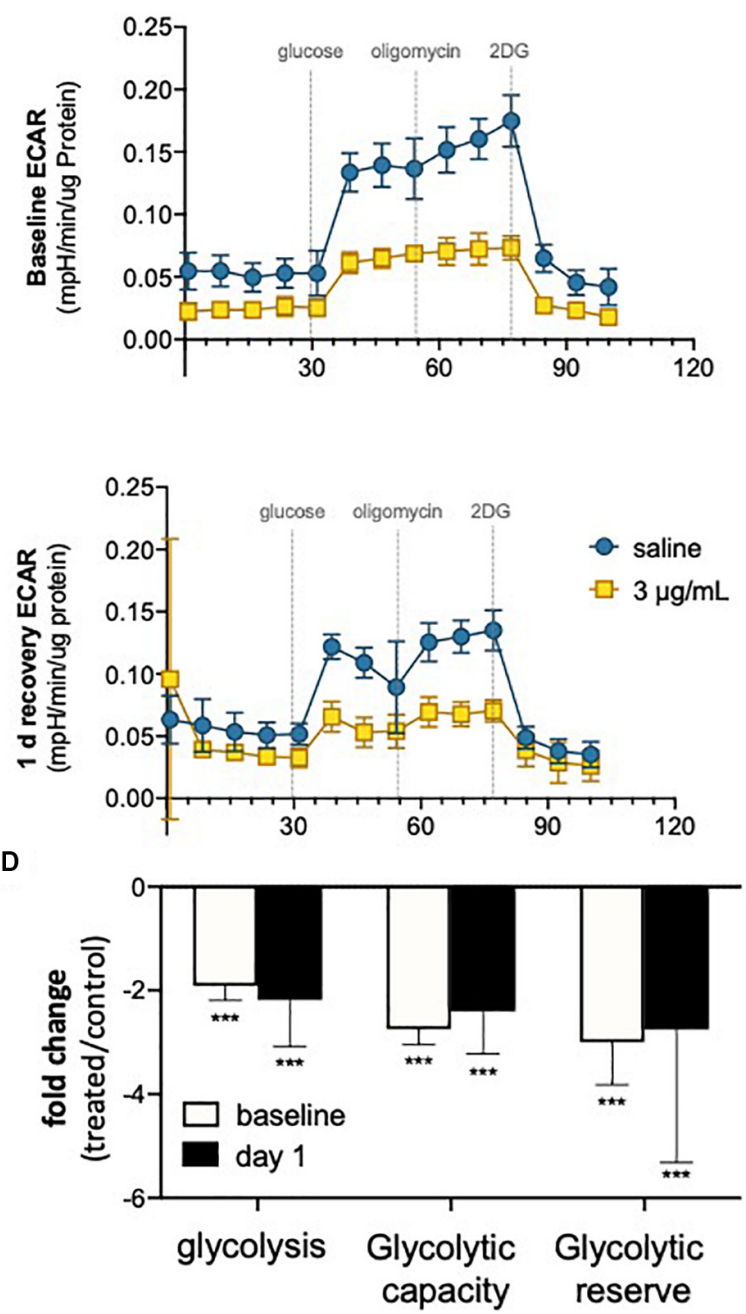

FIGURE 4 | Endothelial metabolism is significantly reduced following epirubicin exposure. hUVEC treated with saline or epirubicin for 30 min were analyzed immediately (baseline) or after 1 day in drug-free medium. (A) Mitochondria stress tests performed at baseline (upper panel) or after recovery (lower panel). Data presented as mean $\pm \mathrm{SD}, n=8$ wells. (B) Summary chart showing mean fold-change $\pm \mathrm{SEM}$ of mitochondrial respiration parameters (treated/control) (C) ECAR measurements obtained from glycolysis stress test are shown for baseline and following 1 day recovery, (upper and lower charts, respectively); as in (A), data represents mean $\pm \mathrm{SD}, n=8$ wells. (D) summary graph of relevant glycolytic parameters, showing mean fold-change (treated/control) \pm SEM. Student's $t$-tests were used to assert significance of differences between treatment and saline controls, ${ }^{* \star *} p<0.0001$ and ${ }^{*} p<0.05$.

images are shown in Figure 6B. Images were systematically analyzed in batches to quantify multiple vascular parameters known to be affected locally by intrinsic EC properties, such as the ones assessed previously in hUVEC. Vascular density (left panel), vessel diameter (middle panel) and pericyte: EC ratio, as a measure of pericyte coverage and vascular integrity were quantified (Figure 6C). Consistent with what was observed in the ex vivo experiments (Figure 5), a significant decrease in vascular density (Figure 6C, left) was seen only after 7 days, but not immediately after injection (1 day). Surprisingly, animals that received two epirubicin injections within the same week, also had reduced vascular density but not different from mice that received only one treatment. This may suggest that cells are either less responsive, or that indeed it takes more than 3 days for a cumulative effect to manifest in vivo.

Vessel diameter (Figure 6C, middle) was not altered, consistent with an also constant pericyte: EC ratio (Figure 6C, right) among all treatment groups, which suggests a vessel pruning effect (reduction in number of vessels) but not a change in integrity or caliber of blood vessels.

\section{Epirubicin Treatment Promotes Myeloid Cell Infiltration Into the Lung}

Our results in hUVEC show that one of the most striking reprogramming events taking place in response to sub-lethal 


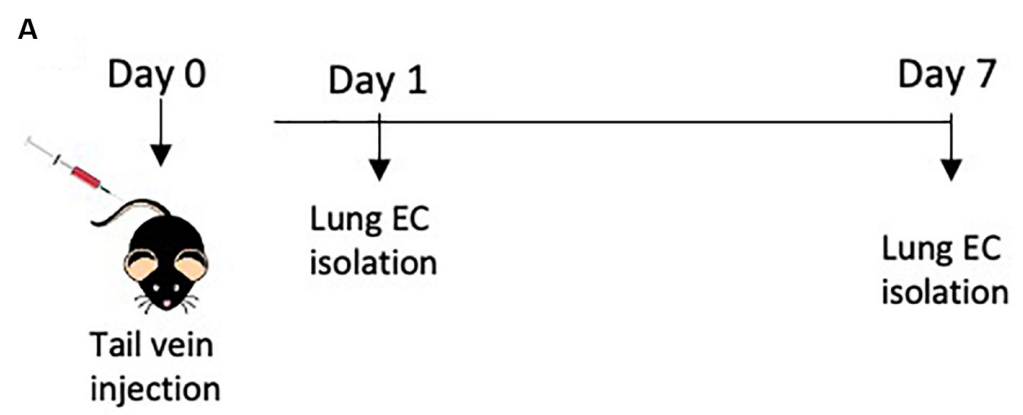

B
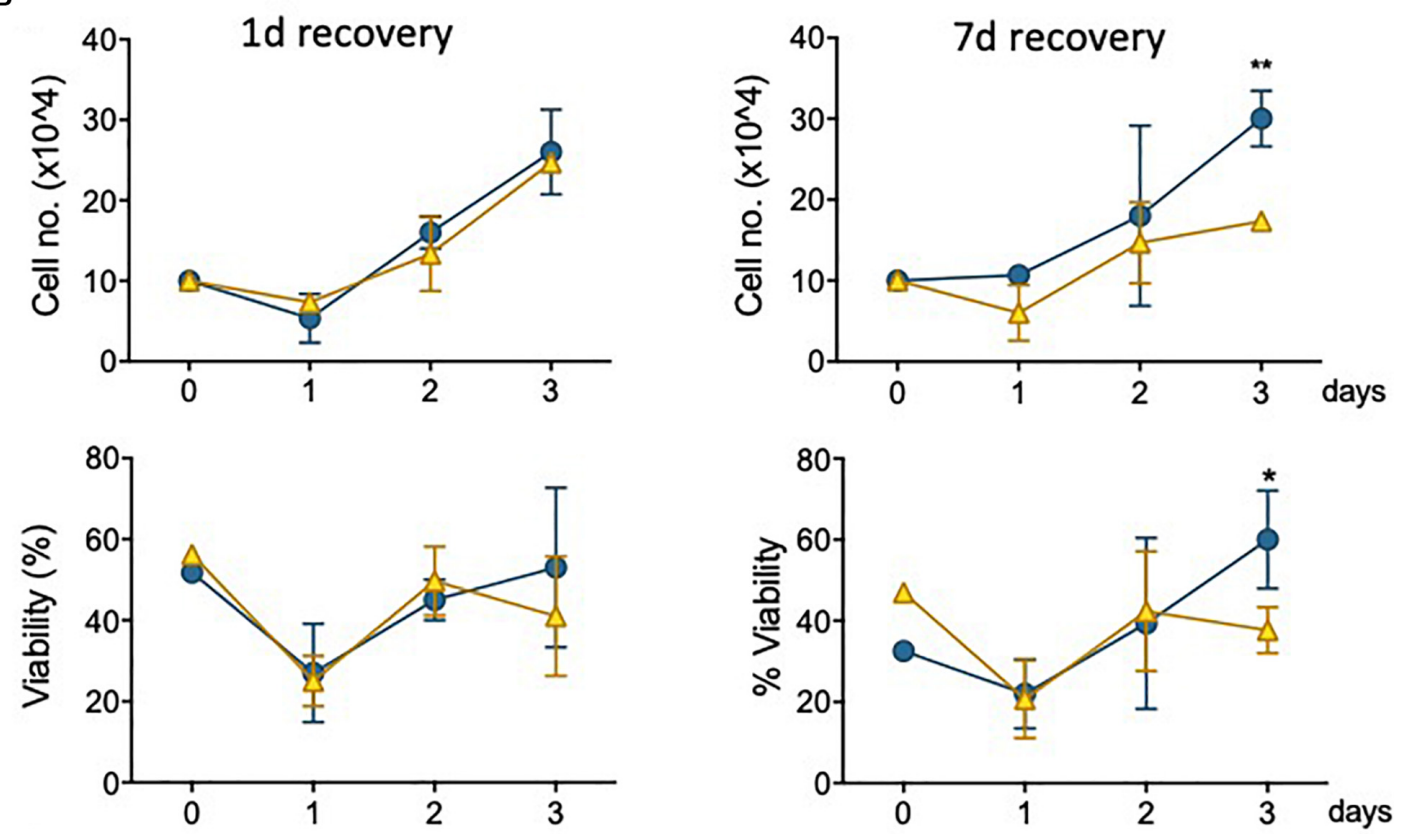

C
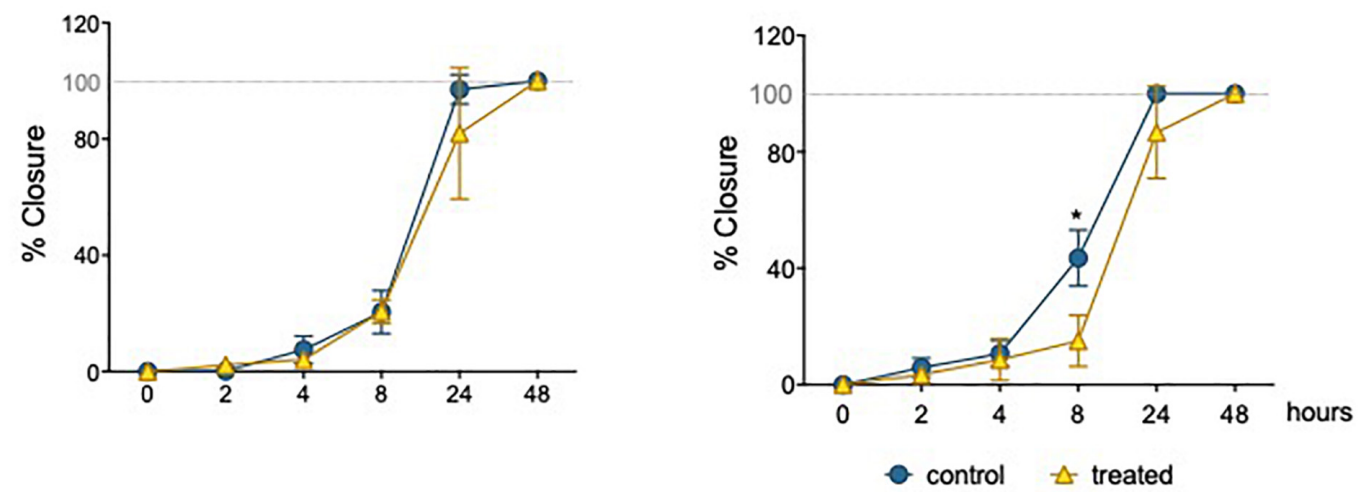

FIGURE 5 | Primary lung MVEC isolated epirubicin-treated mice: effects on viability and migration. (A) Experiment outline EC exposure in vivo; C57BL/6 mice received intravenous epirubicin or saline control, and lung MVEC were isolated 1 and 7 days post injection. Lung MVEC cultures were established and assays performed with cells at P1. (B) Cells isolated 1 day (left) and 7 days (right) were used to quantitatively compare their proliferation (upper panels) and viability (lower panels). (C) Migration assay of P1 lung MVEC obtained after 1 or 7 days of mice that received saline control or epirubicin injections. Data displayed as mean \pm SD of three independent replicates, unpaired $t$-tests used for analysis, ${ }^{*} p<0.05,{ }^{\star *} p<0.01$.

epirubicin exposure is that of driving senescence. Consistent with a senescent-like morphology and positive staining for senescence marker SA- $\beta$-gal (Figure 2, Supplementary Figure S1), a pro-inflammatory SASP-like cytokine profile was also observed. Using sections obtained from the mice in the previous experimental set-up (Figure 6A), we used a general 


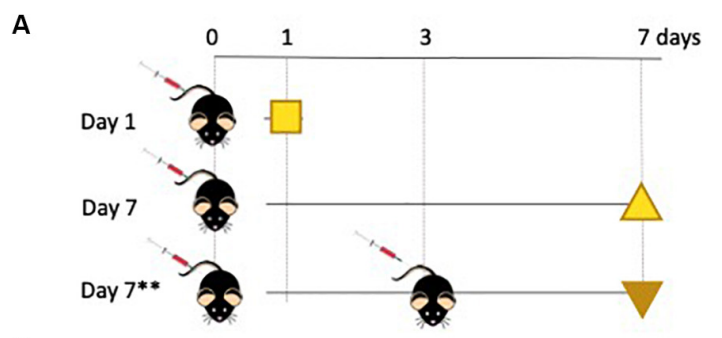

B Podocalyxin

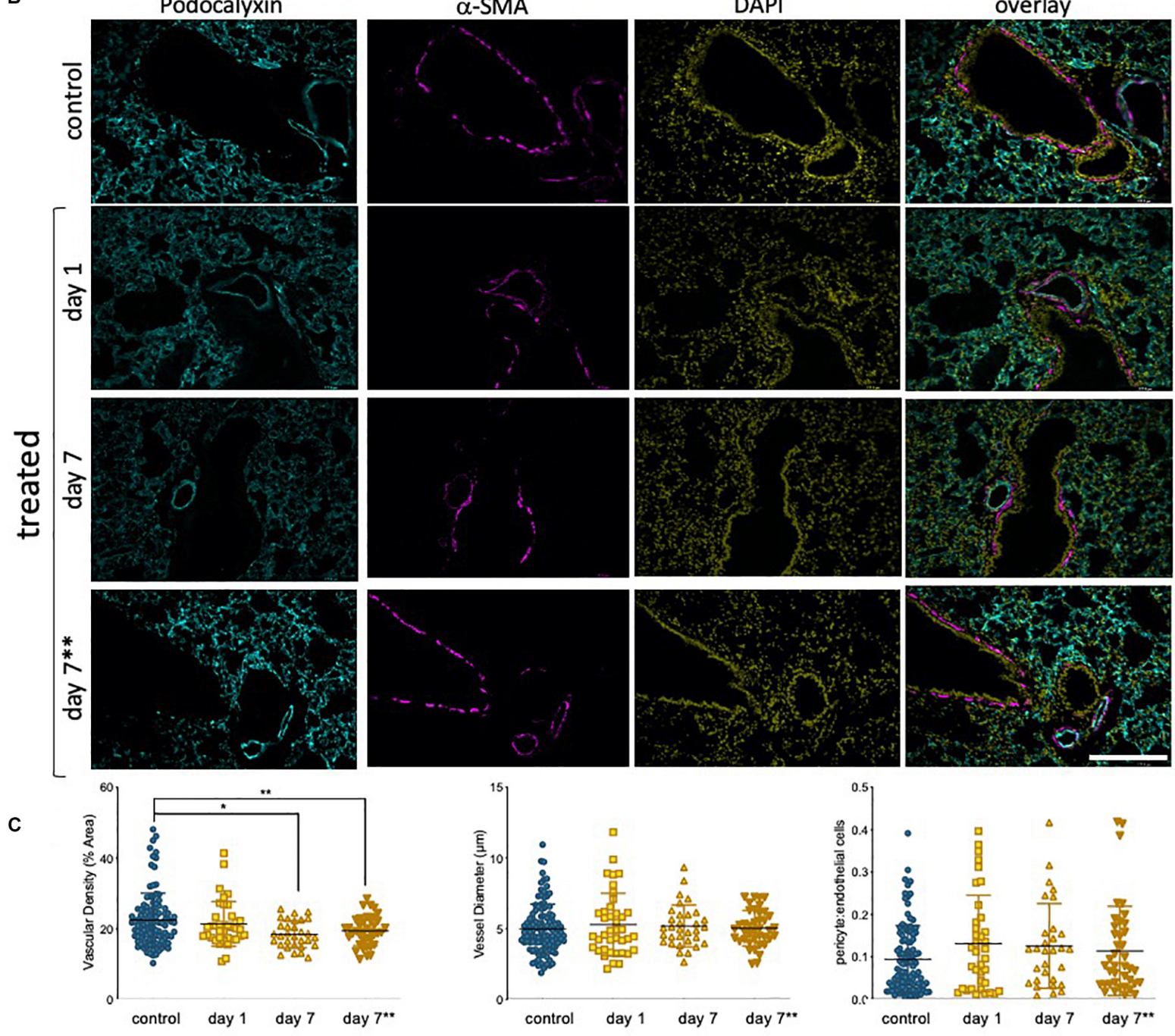

FIGURE 6 | Lung vascularity decreases in epirubicin-treated mice 7 days post injection. (A) Experiment outline: 6-8 week-old C57BL/6 mice received intravenous epirubicin or saline injections, and tissue harvested and analyzed day 1 or day 7 post injection. A third group of animals were re-injected at day 3 and lungs harvested on day $7^{\star \star}$. (B) Representative images of lung sections stained with endothelial marker (Podocalyxin, Cyan), pericyte marker ( $\alpha$-SMA, Magenta) and counterstained with nuclear marker DAPI (Yellow); Scale bar = $200 \mu \mathrm{m}$ (C) Vascular parameters were analyzed using Image J. Vascular density (average\% area $\pm \mathrm{SD}$ ), vessel diameter (average $\mu \mathrm{m} \pm \mathrm{SD}$ ) and Pericyte coverage (displayed as a ratio of pericyte: EC signal). Charts combine data from eight sections per animal, three images per section (4,5 animals per group, saline controls are combined); statistical significance was assessed by one-way ANOVA with Dunnett's Multiple Comparison Test, and ${ }^{\star} p<0.05,{ }^{* *} p<0.01$.

myeloid cell marker (Mac 2, (Ho and Springer, 1982) to quantify inflammatory cell infiltration into lungs following epirubicin treatment (Figure 7A). This is a critical parameter, as macrophage infiltration and activation status mediated vascular remodeling and organ microenvironment (Wenes et al., 2016; Zhang et al., 2020). The number of Mac2+ cells was systematically quantified using batch analyses and "particle analysis" function (ImageJ). Unlike what is seen for vascular 
parameters, myeloid cell infiltration occurs as soon as 1 day following epirubicin treatment, and is maintained consistently higher than the controls after 7 day. Animals in group receiving two injections $\left(7^{* *}\right)$ also had a higher number of Mac- $2+$ cells, but less than either of the other two treatment groups. This was unexpected but could be a result of epirubicin treatment compromising survival and/or proliferation of Mac-2+ cells that infiltrate the lung after the first injection. Combined, and correlating with an increase in EC-derived pro-inflammatory cytokine profile (Figures 2C,D), these results show that there is an increase in myeloid cell recruitment to lungs of epirubicin-treated animals.

\section{DISCUSSION}

The vascular endothelium is a critical barrier maintaining homeostasis between circulating blood and surrounding tissues. It is responsible for various functions including maintaining vascular tone, preventing platelet aggregation, and regulating extravasation and angiogenesis, as well as inflammatory responses (Sabbatinelli et al., 2017; Kruger-Genge et al., 2019), ultimately regulating organ perfusion. The association of anthracycline treatment with endothelial dysfunction at the injection site has been demonstrated (Yamada et al., 2012; Sato et al., 2014). This study investigates the effects of low dose epirubicin on EC and aimed to model the exposure of distant microvascular networks to this drug in vivo. Epirubicin is considered a milder anthracycline than the most commonly used doxorubicin (Khasraw et al., 2012; Gajalakshmi et al., 2013), but even though its effects on cardiac tissue are less, the systemic effects on other somatic cells are not known. This is important to assess the nature, extent and potential reversibility of vascular responses to epirubicin, and to infer possible secondary disease following cancer treatment, downstream of endothelial reprogramming.

As expected, our results show a significant decrease in EC number and viability over time as a result of epirubicin treatment (Figure 1): clinical doses of epirubicin can cause significant levels of cell death in hUVEC, but lower doses $(3 \mu \mathrm{g} / \mathrm{mL})$ result preferentially in the induction of senescence (Figure 2). This response has been previously associated with treatment with Doxorubicin, and shown to impact on regenerative function (Yasuda et al., 2010; Wojcik et al., 2015; Cappetta et al., 2018).

Although EC function has been demonstrated to be regulated downstream of metabolic reprogramming (Bierhansl et al., 2017), metabolic activity of senescent EC is not particularly well described. Concomitant with a decrease in parameters of EC function assessed either ex vivo (Figure 3) or in primary cells isolated following in vivo exposure (Figure 5), we see a dramatic decrease in metabolic activity in hUVEC exposed to $3 \mu \mathrm{g} / \mathrm{mL}$ epirubicin (Figure 4). Previous reports have associated senescence with increased metabolic activity due to acquisition of SASP (Wiley and Campisi, 2016). Glycolysis was shown to be elevated in senescent human diploid fibroblasts (Bittles and Harper, 1984; James et al., 2015), however, glycolysis upregulation is not typical in senescent EC (Unterluggauer et al., 2008), and instead a decrease in glycolysis has been observed as a result of PFKFB3 activity (Kuosmanen et al., 2018). Here, we show a striking and immediate decrease in glycolytic activity, capacity and reserve (Figures 4C,D) that persists for at least $24 \mathrm{~h}$ after recovery in complete medium. Mitochondrial respiration also decreases, mostly the basal respiration rates, and at a more gradual pace, becoming significantly more pronounced 1 day after treatment.

The resulting and expectedly sharp drop in ATP availability would result in a decrease in energy-demanding aspects of EC behavior. In fact, a decrease in angiogenic potential and wound-healing ability is seen as a result of epirubicin treatment (Figures 3, 5), as well as severe downregulation of transcriptional activity (Park et al., 2013; Zecchin et al., 2017) (Supplementary Figure S3A). Interestingly, and unexpectedly $\mathrm{NF \kappa B}$ transcriptional activation is seen to decrease; this conflicts with increased pro-inflammatory cytokine profile in EC (Liu et al., 2017; Lingappan, 2018), and NFkB’s well described activation in response to multiple cellular stresses. Assessment at higher dose or earlier time-points would be necessary to elucidate this further. Nevertheless, remarkably reduced activation was that observed for SMAD and Sp1, both of which linked to vital EC functions. SMAD is a key regulator of angiogenesis (Lin et al., 2016), vascular stability and vascular remodeling (Lan et al., 2007; Itoh et al., 2012); importantly for patients undergoing treatment for cancer, SMAD deletion has been associated with increased metastatic disease (Yang et al., 2017).

$\mathrm{Sp} 1$ has been associated with cell proliferation, differentiation, apoptosis, and senescence (Beishline and Azizkhan-Clifford, 2015), and is also an important transcriptional regulator of VEGF, and thus plays a direct role in angiogenesis (Ko and Kim, 2018). It may indeed play also an indirect role in management of cellular energy metabolism, as decreased VEGF levels (as seen in Supplementary Figure S3) have been shown to result in decreased glycolysis (De Bock et al., 2013). VEGF inhibition has also been associated with endothelial senescence, via elevated intracellular reactive oxygen species (ROS) (Mongiardi et al., 2019).

Importantly, cell senescence is associated with an inflammatory microenvironment (Coppé et al., 2008; Kuilman et al., 2008; Wajapeyee et al., 2008), identified in epirubicintreated hUVEC conditioned medium (Figures 2C,D). The effects of inflammation in vascular function are notably reciprocal, and associated with a myriad of chronic health conditions, such as diabetes, aging and neurodegeneration and multiple respiratory syndromes (Augustin and Koh, 2017; Reiterer and Branco, 2020).

Epirubicin, although with much milder associated cardiotoxicity than other anthracyclines, is shown here to promote endothelial secretion of IL-6 and IL-8 (Childs et al., 2015), previously linked to senescence and increased tumorigenesis (Ortiz-Montero et al., 2017), which in turn may be associated with increased risk of metastatic disease. Additionally, monocyte recruitment and activation signals, such as CCL2 and G-CSF (Coppé et al., 2008; Eggert et al., 2016; 
Figure 2), are also pro-tumorigenic. These increased monocyte recruitment signals seen in hUVEC treated with epirubicin correlate with significantly elevated myeloid cell infiltration (Mac-2+ cells) into lungs of epirubicin-treated mice compared to saline controls (Figure 7). This effect, seen $24 \mathrm{~h}$ after injection, is not reversed within 1 week. Interestingly, however, it is not further increased if the animals receive a second injection 3 days apart. This can be a result of senescent cells being either unresponsive to the subsequent stimulus, or unable to increase the pro-inflammatory signal. It is also possible that myeloid cells present in the tissue following the first injection will undergo apoptosis in the acute phase of response to the second injection. This can only be confirmed with additional time points and co-staining experiments, in which the response of other cells types is evaluated.

Microvascular EC in live tissue are more plastic and versatile than their venous counterparts (Augustin and Koh, 2017). hUVEC are a trusted and reproducible model for the study

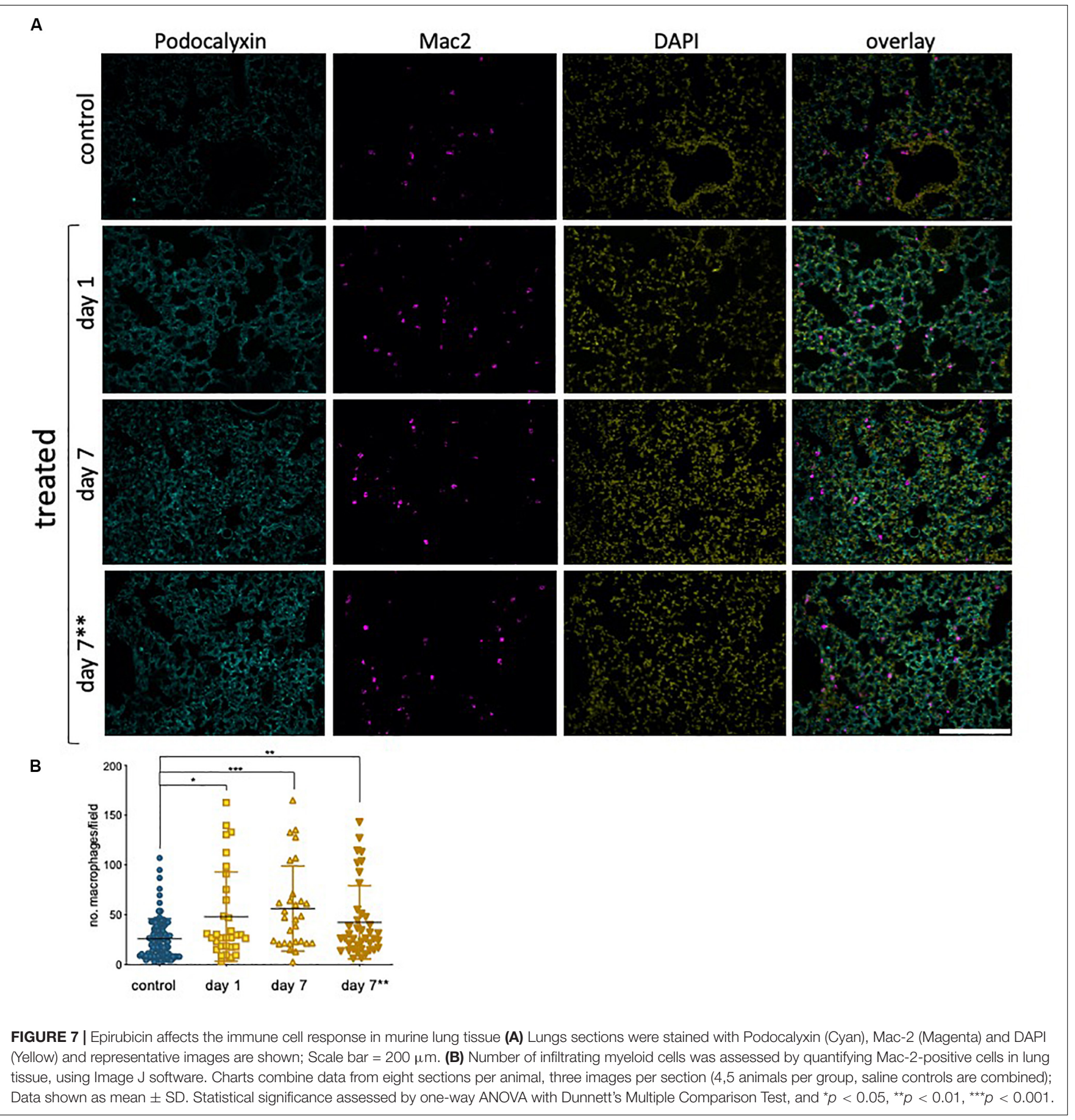


of EC biology, however, to infer if the effects seen were translatable to their microvascular counterparts, we assessed primary microvascular EC isolated from mouse lungs following epirubicin treatment. This allowed the confirmation that EC are affected by epirubicin when the exposure occurs in vivo, via evaluation of functional parameters (Figure 5), but also the potential protective effect exerted by other cells within the tissue. This is supported the fact that vascular regression (Figure 6) and inflammatory cell infiltration (Figure 7) are not intensified with a second injection; however, and very importantly, the effects are also not reversed, which supports the premise of tissue remodeling and long-term changes in microvascular and organ function following treatment.

One of the major risks associated with cancer is distant recurrence, and recent evidence indicates that chemotherapy treatment can potentiate metastatic disease (Chabner, 2018). For example, Paclitaxel and Doxorubicin have been shown to facilitate intravasation in human xenograft models of breast cancer, with concomitant increase in secondary tumors (Karagiannis et al., 2017). Besides EC, other cells such as macrophages secrete proinflammatory cytokines such as IL-6 and IL-12 following chemotherapy (Bryniarski et al., 2009), further promoting cancer cell proliferation and metastasis (Liu et al., 2015). These studies focus on the effects of chemotherapy in the tumor vasculature but overlook that of tumor-free organs. Disrupting MVEC integrity, signaling and barrier function (Figure 3B, Supplementary Figure S2B) happens at low dose exposure to epirubicin in EC. Little is known about the mechanisms that lead to drug-promoting metastasis via vascular rearrangements, but these results suggest that endothelial disruption by sublethal exposure to epirubicin could facilitate extravasation and metastatic colonization, especially when combined with an inflammatory microenvironment. This study aimed to strictly dissect the effects of epirubicin on naïve vasculature, not also primed by tumor-derived signals. Further studies to include tumor-bearing mice will allow the examination of the combined effects of cancer and treatment, as well as the association between cytotoxic treatment and disease progression and metastasis.

Clinically, cancer patients are exposed to long term, cumulative treatment strategies. Our results show that despite removal of initial epirubicin exposure, over time hUVEC do not recover in vitro. Furthermore, we observed a stable decline in lung vascular density following treatment in vivo, several days after drug clearance from circulation. We propose that vascular responses to epirubicin result in molecular reprogramming and adaptations that are likely to result in tissue remodeling and long-term changes in vascular and organ function. These can potentiate comorbidities associated with treatment, besides increased risk for metastasis. Further understanding of vascular responses in specific organ microenvironment will assist in prediction and prevention of chemotherapyassociated long-term secondary pathologies and survivalassociated morbidity.

\section{DATA AVAILABILITY STATEMENT}

All datasets presented in this study are included in the article/Supplementary Material.

\section{ETHICS STATEMENT}

The animal study was reviewed and approved by the Department of Health, Social Services and Public Safety (NI) Research Ethics Committee at Queen's University, Belfast.

\section{AUTHOR CONTRIBUTIONS}

AJE and TM performed cell proliferation and viability assays. AJE performed all functional assays (angiogenesis, migration, and permeability), as well as cytokine and transcription factor activation screens. TM performed all cytochemistry and hUVEC staining, imaging, and quantification (TUNEL, SA_ $\beta$-Gal, and VE-cadherin) and RTqPCR. AJE and GA performed animal experiments and collected tissue for IF and isolated and maintained primary EC for viability, proliferation, and migration assays. AJE, GA, and NT processed and sectioned tissue for IF. $\mathrm{AB}$ designed, optimized, and performed all the metabolism assays and analyses. AE performed, imaged, and analyzed all murine lung IF staining. CB designed and supervised the study. CB, AJE, and TM wrote the manuscript. All authors made contributions to the final version and proofread the manuscript.

\section{FUNDING}

This work was funded by Breast Cancer Now Scientific Fellowship to CB (2014MaySF275), a Ph.D. studentship from the $\mathrm{DfE}(\mathrm{CB}$ and $\mathrm{AB})$, and supported by generous start-up from the School of Medicine, Dentistry and Biomedical Sciences to CB.

\section{ACKNOWLEDGMENTS}

We would like to thank Niamh McGuckin, Lowri Edwards, and Aaron Johnston for their contribution toward optimization of staining protocols and image analyses and quantification, as well as for their thorough preparation of detailed methodology for batch analyses using ImageJ software. We would also like to acknowledge Dr. Moriz Reiterer for his invaluable contribution to the optimization of isolation and maintenance primary MVEC, as well as technical assistance with the seahorse metabolic assays and analyses. This manuscript is available as a preprint on bioRqiv, and can be found at doi: https://doi.org/10.1101/2020. 06.25.171249.

\section{SUPPLEMENTARY MATERIAL}

The Supplementary Material for this article can be found online at: https://www.frontiersin.org/articles/10.3389/fcell.2020.00799/ full\#supplementary-material 


\section{REFERENCES}

Augustin, H. G., and Koh, G. Y. (2017). Organotypic vasculature: from descriptive heterogeneity to functional pathophysiology. Science 357:eaal2379. doi: 10. $1126 /$ science.aal2379

Babai, F., Musevi-Aghdam, J., Schurch, W., Royal, A., and Gabbiani, G. (1990). Coexpression of alpha-sarcomeric actin, alpha-smooth muscle actin and desmin during myogenesis in rat and mouse embryos I. Skeletal muscle. Differentiation 44, 132-142. doi: 10.1111/j.1432-0436.1990.tb00546.x

Barrett-Lee, P. J., Dixon, J. M., Farrell, C., Jones, A., Leonard, R., Murray, N., et al. (2009). Expert opinion on the use of anthracyclines in patients with advanced breast cancer at cardiac risk. Ann. Oncol. 20, 816-827. doi: 10.1093/annonc/ $\operatorname{mdn} 728$

Beishline, K., and Azizkhan-Clifford, J. (2015). Sp1 and the 'hallmarks of cancer'. FEBS J. 282, 224-258. doi: 10.1111/febs.13148

Bierhansl, L., Conradi, L. C., Treps, L., Dewerchin, M., and Carmeliet, P. (2017). Central role of metabolism in endothelial cell function and vascular disease. Physiology 32, 126-140. doi: 10.1152/physiol.00031.2016

Bittles, A. H., and Harper, N. (1984). Increased glycolysis in ageing cultured human diploid fibroblasts. Biosci. Rep. 4, 751-756. doi: 10.1007/bf01128816

Bryniarski, K., Szczepanik, M., Ptak, M., Zemelka, M., and Ptak, W. (2009). Influence of cyclophosphamide and its metabolic products on the activity of peritoneal macrophages in mice. Pharmacol. Rep. 61, 550-557. doi: 10.1016/ s1734-1140(09)70098-2

Cameron, A. C., Touyz, R. M., and Lang, N. N. (2016). Vascular complications of cancer chemotherapy. Can. J. Cardiol. 32, 852-862.

Cappetta, D., Rossi, F., Piegari, E., Quaini, F., Berrino, L., Urbanek, K., et al. (2018). Doxorubicin targets multiple players: a new view of an old problem. Pharmacol. Res. 127, 4-14. doi: 10.1016/j.phrs.2017.03.016

Chabner, B. A. (2018). Does chemotherapy induce metastases? Oncologist 23, 273-274. doi: 10.1634/theoncologist.2017-0648

Childs, B. G., Durik, M., Baker, D. J., and van Deursen, J. M. (2015). Cellular senescence in aging and age-related disease: from mechanisms to therapy. Nat. Med. 21, 1424-1435. doi: 10.1038/nm.4000

Coppé, J. P., Patil, C. K., Rodier, F., Sun, Y., Muñoz, D. P., Goldstein, J., et al. (2008). Senescence-associated secretory phenotypes reveal cellnonautonomous functions of oncogenic RAS and the p53 tumor suppressor. PLoS Biol. 6:e301. doi: 10.1371/journal.pbio.0060301

De Bock, K., Georgiadou, M., Schoors, S., Kuchnio, A., Wong, B. W., Cantelmo, A. R., et al. (2013). Role of PFKFB3-driven glycolysis in vessel sprouting. Cell 154, 651-663. doi: 10.1016/j.cell.2013.06.037

Dejana, E., Hirschi, K. K., and Simons, M. (2017). The molecular basis of endothelial cell plasticity. Nat. Commun. 8:14361.

EBCTCG (1988). Effects of adjuvant tamoxifen and of cytotoxic therapy on mortality in early breast cancer. An overview of 61 randomized trials among 28,896 women. N. Engl. J. Med. 319, 1681-1692. doi: 10.1056/ nejm 198812293192601

EBCTCG (2005). Effects of chemotherapy and hormonal therapy for early breast cancer on recurrence and 15-year survival: an overview of the randomised trials. Lancet 365, 1687-1717. doi: 10.1016/s0140-6736(05)66544-0

Edwardson, D. W., Narendrula, R., Chewchuk, S., Mispel-Beyer, K., Mapletoft, J. P., and Parissenti, A. M. (2015). Role of drug metabolism in the cytotoxicity and clinical efficacy of anthracyclines. Curr. Drug Metab. 16, 412-426. doi: $10.2174 / 1389200216888150915112039$

Eggert, T., Wolter, K., Ji, J., Ma, C., Yevsa, T., Klotz, S., et al. (2016). Distinct functions of senescence-associated immune responses in liver tumor surveillance and tumor progression. Cancer Cell 30, 533-547. doi: 10.1016/j. ccell.2016.09.003

Ewald, J. A., Desotelle, J. A., Wilding, G., and Jarrard, D. F. (2010). Therapyinduced senescence in cancer. J. Natl. Cancer Inst. 102, 1536-1546.

Fukuokaya, W., Kimura, T., Miki, J., Kimura, S., Watanabe, H., Bo, F., et al. (2020). Effectiveness of intravesical doxorubicin immediately following resection of primary non-muscle-invasive bladder cancer: a propensity score-matched analysis. Clin. Genitourin. Cancer 18, e55-e61. doi: 10.1016/j.clgc.2019.09.005

Gajalakshmi, P., Priya, M. K., Pradeep, T., Behera, J., Muthumani, K., Madhuwanti, S., et al. (2013). Breast cancer drugs dampen vascular functions by interfering with nitric oxide signaling in endothelium. Toxicol. Appl. Pharmacol. 269, 121-131. doi: 10.1016/j.taap.2013.03.011
Gianni, L., Norton, L., Wolmark, N., Suter, T. M., Bonadonna, G., and Hortobagyi, G. N. (2009). Role of anthracyclines in the treatment of early breast cancer. J. Clin. Oncol. 27, 4798-4808. doi: 10.1200/jco.2008.21.4791

Heiss, C., Rodriguez-Mateos, A., and Kelm, M. (2015). Central role of eNOS in the maintenance of endothelial homeostasis. Antioxid. Redox. Signal. 22, 1230-1242. doi: 10.1089/ars.2014.6158

Ho, M. K., and Springer, T. A. (1982). Mac-2, a novel 32,000 Mr mouse macrophage subpopulation-specific antigen defined by monoclonal antibodies. J. Immunol. $128,1221-1228$.

Itoh, F., Itoh, S., Adachi, T., Ichikawa, K., Matsumura, Y., Takagi, T., et al. (2012). $\mathrm{Smad} 2 / \mathrm{Smad} 3$ in endothelium is indispensable for vascular stability via S1PR1 and N-cadherin expressions. Blood 119, 5320-5328. doi: 10.1182/blood-201112-395772

James, E. L., Michalek, R. D., Pitiyage, G. N., de Castro, A. M., Vignola, K. S., Jones, J., et al. (2015). Senescent human fibroblasts show increased glycolysis and redox homeostasis with extracellular metabolomes that overlap with those of irreparable DNA damage, aging, and disease. J. Proteome Res. 14, 1854-1871. doi: $10.1021 /$ pr501221g

Jones, L. W., Haykowsky, M. J., Swartz, J. J., Douglas, P. S., and Mackey, J. R. (2007). Early breast cancer therapy and cardiovascular injury. J. Am. Coll. Cardiol. 50, 1435-1441.

Karagiannis, G. S., Pastoriza, J. M., Wang, Y., Harney, A. S., Entenberg, D., Pignatelli, J., et al. (2017). Neoadjuvant chemotherapy induces breast cancer metastasis through a TMEM-mediated mechanism. Sci. Transl. Med. 9:eaan0026. doi: 10.1126/scitranslmed.aan0026

Kennecke, H., Yerushalmi, R., Woods, R., Cheang, M. C., Voduc, D., Speers, C. H., et al. (2010). Metastatic behavior of breast cancer subtypes. J. Clin. Oncol. 28, 3271-3277.

Khasraw, M., Bell, R., and Dang, C. (2012). Epirubicin: is it like doxorubicin in breast cancer? A clinical review. Breast 21, 142-149. doi: 10.1016/j.breast.2011. 12.012

Ko, D., and Kim, S. (2018). Cooperation between ZEB2 and Sp1 promotes cancer cell survival and angiogenesis during metastasis through induction of survivin and VEGF. Oncotarget 9, 726-742. doi: 10.18632/oncotarget.23139

Kruger-Genge, A., Blocki, A., Franke, R. P., and Jung, F. (2019). Vascular endothelial cell biology: an update. Int. J. Mol. Sci. 20:4411. doi: 10.3390/ ijms20184411

Kuilman, T., Michaloglou, C., Vredeveld, L. C., Douma, S., van Doorn, R., Desmet, C. J., et al. (2008). Oncogene-induced senescence relayed by an interleukindependent inflammatory network. Cell 133, 1019-1031. doi: 10.1016/j.cell. 2008.03.039

Kuosmanen, S. M., Sihvola, V., Kansanen, E., Kaikkonen, M. U., and Levonen, A. L. (2018). MicroRNAs mediate the senescence-associated decline of NRF2 in endothelial cells. Redox Biol. 18, 77-83. doi: 10.1016/j.redox.2018.06.007

Lan, Y., Liu, B., Yao, H., Li, F., Weng, T., Yang, G., et al. (2007). Essential role of endothelial Smad4 in vascular remodeling and integrity. Mol. Cell. Biol. 27, 7683-7692. doi: 10.1128/mcb.00577-07

Le Tourneau, C., Lee, J. J., and Siu, L. L. (2009). Dose escalation methods in phase I cancer clinical trials. J. Natl. Cancer Inst. 101, 708-720. doi: 10.1093/jnci/djp079

Li, J., Li, Y., Brophy, P. D., and Kershawt, D. B. (2001). Gene structure and alternative splicing of murine podocalyxin: a member of the CD34 sialomucin family. DNA Seq. 12, 407-412. doi: 10.3109/10425170109084466

Lin, S., Xie, J., Gong, T., Shi, S., Zhang, T., Fu, N., et al. (2016). Smad signal pathway regulates angiogenesis via endothelial cell in an adipose-derived stromal cell/endothelial cell co-culture, 3D gel model. Mol. Cell. Biochem. 412, 281-288. doi: 10.1007/s11010-015-2634-5

Lingappan, K. (2018). NF-кB in oxidative stress. Curr. Opin. Toxicol. 7, 81-86.

Liu, J., Lin, P. C., and Zhou, B. P. (2015). Inflammation fuels tumor progress and metastasis. Curr. Pharm. Des. 21, 3032-3040. doi: 10.2174/ 1381612821666150514105741

Liu, T., Zhang, L., Joo, D., and Sun, S. C. (2017). NF-кB signaling in inflammation. Signal. Transduct. Target Ther. 2:17023.

Lori, J. C., Stein, T. J., and Thamm, D. H. (2010). Doxorubicin and cyclophosphamide for the treatment of canine lymphoma: a randomized, placebo-controlled study. Vet. Comp. Oncol. 8, 188-195.

Martin, A. M., Cagney, D. N., Catalano, P. J., Warren, L. E., Bellon, J. R., Punglia, R. S., et al. (2017). Brain metastases in newly diagnosed breast cancer: a population-based study. JAMA Oncol. 3, 1069-1077. 
Mercuro, G., Cadeddu, C., Piras, A., Dessì, M., Madeddu, C., Deidda, M., et al. (2007). Early epirubicin-induced myocardial dysfunction revealed by serial tissue Doppler echocardiography: correlation with inflammatory and oxidative stress markers. Oncologist 12, 1124-1133. doi: 10.1634/theoncologist.12-91124

Mongiardi, M. P., Radice, G., Piras, M., Stagni, V., Pacioni, S., Re, A., et al. (2019). Axitinib exposure triggers endothelial cells senescence through ROS accumulation and ATM activation. Oncogene 38, 5413-5424. doi: 10.1038/ s41388-019-0798-2

NICE (2020). Cytotoxic Drugs. Available online at: https://bnf.nice.org.uk/ treatment-summary/cytotoxic-drugs.html (accessed May 26, 2020).

Ortiz-Montero, P., Londoño-Vallejo, A., and Vernot, J. P. (2017). Senescenceassociated IL-6 and IL-8 cytokines induce a self- and cross-reinforced senescence/inflammatory milieu strengthening tumorigenic capabilities in the MCF-7 breast cancer cell line. Cell Commun. Signal. 15:17.

Pagès, G., and Pouysségur, J. (2005). Transcriptional regulation of the vascular endothelial growth factor gene-a concert of activating factors. Cardiovasc. Res. 65, 564-573. doi: 10.1016/j.cardiores.2004.09.032

Park, C., Kim, T. M., and Malik, A. B. (2013). Transcriptional regulation of endothelial cell and vascular development. Circ. Res. 112, 1380-1400. doi: 10.1161/circresaha.113.301078

Reiterer, M., and Branco, C. M. (2020). Endothelial cells and organ function: applications and implications of understanding unique and reciprocal remodelling. FEBS J. 287, 1088-1100. doi: 10.1111/febs.15143

Reiterer, M., Colaco, R., Emrouznejad, P., Jensen, A., Rundqvist, H., Johnson, R. S., et al. (2019). Acute and chronic hypoxia differentially predispose lungs for metastases. Sci. Rep. 9:10246.

Robert, J. (1994). Clinical pharmacokinetics of epirubicin. Clin. Pharmacokinet. 26, 428-438. doi: 10.2165/00003088-199426060-00002

Sabbatinelli, J., Vignini, A., Salvolini, E., Nanetti, L., Mazzanti, L., and Anna Rabini, R. (2017). Platelet-derived NO in subjects affected by Type 2 diabetes with and without complications: is there any relationship with their offspring? Exp. Clin. Endocrinol. Diabetes 125, 290-296. doi: 10.1055/s-0043-102578

Sato, Y., Kondo, M., Inagaki, A., Komatsu, H., Okada, C., Naruse, K., et al. (2014). Highly frequent and enhanced injection site reaction induced by peripheral venous injection of fosaprepitant in anthracycline-treated patients. J. Cancer 5 , 390-397. doi: 10.7150/jca.7706

Sonowal, H., Pal, P., Shukla, K., Saxena, A., Srivastava, S. K., and Ramana, K. V. (2018). Aldose reductase inhibitor, fidarestat prevents doxorubicin-induced endothelial cell death and dysfunction. Biochem. Pharmacol. 150, 181-190. doi: 10.1016/j.bcp.2018.02.018

Swain, S. M., Whaley, F. S., and Ewer, M. S. (2003). Congestive heart failure in patients treated with doxorubicin: a retrospective analysis of three trials. Cancer 97, 2869-2879. doi: 10.1002/cncr.11407

Szuławska, A., and Czyz, M. (2006). Molecular mechanisms of anthracyclines action. Postepy. Hig. Med. Dosw. 60, 78-100.

U.S. Department of Health and Human Services, Food and Drug Administration, and Center for Drug Evaluation, and Research (2005). Estimating the Maximum Safe Starting Dose in Initial Clinical Trials for Therapeutics in Adult Healthy Volunteers. Silver Spring, MD: FDA.
Unterluggauer, H., Mazurek, S., Lener, B., Hütter, E., Eigenbrodt, E., Zwerschke, W., et al. (2008). Premature senescence of human endothelial cells induced by inhibition of glutaminase. Biogerontology 9, 247-259. doi: 10.1007/s10522-0089134-x

Wajapeyee, N., Serra, R. W., Zhu, X., Mahalingam, M., and Green, M. R. (2008). Oncogenic BRAF induces senescence and apoptosis through pathways mediated by the secreted protein IGFBP7. Cell 132, 363-374. doi: 10.1016/j.cell. 2007.12.032

Wenes, M., Shang, M., Di Matteo, M., Goveia, J., Martín-Pérez, R., Serneels, J., et al. (2016). Macrophage metabolism controls tumor blood vessel morphogenesis and metastasis. Cell Metab. 24, 701-715. doi: 10.1016/j.cmet.2016.09.008

Wiley, C. D., and Campisi, J. (2016). From ancient pathways to aging cellsconnecting metabolism and cellular senescence. Cell Metab. 23, 1013-1021. doi: 10.1016/j.cmet.2016.05.010

Wojcik, T., Buczek, E., Majzner, K., Kolodziejczyk, A., Miszczyk, J., Kaczara, P., et al. (2015). Comparative endothelial profiling of doxorubicin and daunorubicin in cultured endothelial cells. Toxicol. Vitro 29, 512-521. doi: 10.1016/j.tiv.2014.12.009

Xiao, W., Zheng, S., Yang, A., Zhang, X., Zou, Y., Tang, H., et al. (2018). Breast cancer subtypes and the risk of distant metastasis at initial diagnosis: a population-based study. Cancer Manag. Res. 10, 5329-5338. doi: 10.2147/cmar. s176763

Yamada, T., Egashira, N., Bando, A., Nishime, Y., Tonogai, Y., Imuta, M., et al. (2012). Activation of p38 MAPK by oxidative stress underlying epirubicininduced vascular endothelial cell injury. Free Radic. Biol. Med. 52, 1285-1293. doi: 10.1016/j.freeradbiomed.2012.02.003

Yang, J., Wang, Y., Zeng, Z., Qiao, L., Zhuang, L., Gao, Q., et al. (2017). Smad4 deletion in blood vessel endothelial cells promotes ovarian cancer metastasis. Int. J. Oncol. 50, 1693-1700. doi: 10.3892/ijo.2017.3957

Yasuda, K., Park, H. C., Ratliff, B., Addabbo, F., Hatzopoulos, A. K., Chander, P., et al. (2010). Adriamycin nephropathy: a failure of endothelial progenitor cell-induced repair. Am. J. Pathol. 176, 1685-1695.

Zecchin, A., Kalucka, J., Dubois, C., and Carmeliet, P. (2017). How endothelial cells adapt their metabolism to form vessels in tumors. Front. Immunol. 8:1750. doi: 10.3389/fimmu.2017.01750

Zhang, J., Muri, J., Fitzgerald, G., Gorski, T., Gianni-Barrera, R., Masschelein, E., et al. (2020). Endothelial lactate controls muscle regeneration from ischemia by inducing M2-like macrophage polarization. Cell Metab. 31, 1136-1153.

Conflict of Interest: The authors declare that the research was conducted in the absence of any commercial or financial relationships that could be construed as a potential conflict of interest.

Copyright (c) 2020 Eakin, Mc Erlain, Burke, Eaton, Tipping, Allocca and Branco. This is an open-access article distributed under the terms of the Creative Commons Attribution License (CC BY). The use, distribution or reproduction in other forums is permitted, provided the original author(s) and the copyright owner(s) are credited and that the original publication in this journal is cited, in accordance with accepted academic practice. No use, distribution or reproduction is permitted which does not comply with these terms. 